\title{
Decreased Tissue COX5B Expression and Mitochondrial Dysfunction during Sepsis-Induced Kidney Injury in Rats
}

\author{
Jochen Hinkelbein, ${ }^{1}$ Lennert Böhm, ${ }^{1}$ Stefan Braunecker, ${ }^{1}$ Christoph Adler, ${ }^{2}$ \\ Edoardo De Robertis, ${ }^{3}$ and Fabrizio Cirillo ${ }^{1,3}$ \\ ${ }^{1}$ Department of Anaesthesiology and Intensive Care Medicine, University Hospital Cologne, Kerpener Str. 62, \\ 50937 Cologne, Germany \\ ${ }^{2}$ Department of Cardiology, University Hospital Cologne, Kerpener Str. 62, 50937 Cologne, Germany \\ ${ }^{3}$ Department of Neurosciences, Reproductive and Odontostomatological Sciences, University of Naples "Federico II", \\ Via S. Pansini, No. 5, 80131 Napoli, Italy
}

Correspondence should be addressed to Jochen Hinkelbein; jochen.hinkelbein@gmail.com

Received 4 July 2016; Revised 6 October 2016; Accepted 8 December 2016; Published 26 January 2017

Academic Editor: Ajit Vikram

Copyright ( $(2017$ Jochen Hinkelbein et al. This is an open access article distributed under the Creative Commons Attribution License, which permits unrestricted use, distribution, and reproduction in any medium, provided the original work is properly cited.

\begin{abstract}
Background. Sepsis is defined as a life-threatening organ dysfunction due to a dysregulated host response to infection. Sepsis is the dominant cause of acute kidney injury (AKI), accounting for nearly $50 \%$ of episodes of acute renal failure. Signaling cascades and pathways within the kidney are largely unknown and analysis of these molecular mechanisms may enhance knowledge on pathophysiology and possible therapeutic options. Material and Methods. 26 male Wistar rats were assigned to either a sham group (control, $N=6$ ) or sepsis group $(N=20$; cecal ligature and puncture model, 24 and 48 hours after CLP). Surviving rats $(n=12)$ were decapitated at 24 hours (early phase; $n=6$ ) or 48 hours (late phase; $n=6$ ) after CLP and kidneys removed for proteomic analysis. 2D-DIGE and DeCyder 2D software $(t$-test, $P<0.01)$ were used for analysis of significantly regulated protein spots. MALDI-TOF in combination with peptide mass fingerprinting (PMF) as well as Western Blot analysis was used for protein identification. Bioinformatic network analyses (STRING, GeneMania, and PCViz) were used to describe protein-protein interactions. Results. 12 spots were identified with significantly altered proteins $(P<0.01)$ in the three analyzed groups. Two spots could not be identified. Four different proteins were found significantly changed among the groups: major urinary protein (MUP5), cytochrome c oxidase subunit B (COX5b), myosin-6 (MYH6), and myosin-7 (MYH7). A significant correlation with the proteins was found for mitochondrial energy production and electron transport. Conclusions. COX5B could be a promising biomarker candidate since a significant association was found during experimental sepsis in the present study. For future research, COX5B should be evaluated as a biomarker in both human urine and serum to identify sepsis.
\end{abstract}

\section{Introduction}

Sepsis has been recently defined as a life-threatening organ dysfunction due to a dysregulated host response to infection [1]. It is characterized by a specific set of systemic reactions to overwhelming infection $[1,2]$. During clinical course, sepsis is often seriously complicated by renal dysfunction and triggers high mortality $[3,4]$, being the leading cause of death in critically ill patients [5].

The kidney shows extreme metabolic activity and an adequate energy supply is a prerequisite for its multiple functions [6]. Furthermore, sepsis is the dominant cause of acute kidney injury (AKI), accounting for nearly $50 \%$ of episodes of acute renal failure $[7,8]$. AKI has been a common and severe problem in critically ill patients during the last decade [9]. Between $5 \%$ and $20 \%$ of critically ill patients in the intensive care unit (ICU) have at least an episode of AKI [9]. Early identification of those patients at risk for AKI could help clinical decision making [10].

Acute reduction in renal function during sepsis arises from a combination of local ischemia, inflammation, and additional factors $[8,11]$. Sepsis-affected signaling cascades 
and pathways within the kidney are largely unknown. More than 1 million different protein variants are present in the mammalian organism, whose cellular abundance, functional status, and localization vary over time and are influenced by numerous environmental interactions [12]. However, analysis of these molecular mechanisms may enhance knowledge on pathophysiology and possible therapeutic options but may also suggest possible biomarker candidates to identify sepsis early in the clinical course. Unfortunately, patients' kidneys are typically not usable for those analyses. Consequently, animal models are commonly used as replace.

During the last decade, proteomics has increasingly been applied to identify and quantify mitochondrial proteins related to cellular perturbations, which enforce and elaborate data from metabolites and gene sequences, for example, in human mitochondrial disorders [12]. A proteomic approach for identification, quantification, and characterization of proteins of interest in biological materials facilitates understanding the pathogenesis. This approach has been extensively used for several diseases, for example, in sepsis [13-16], hyperoxia [17-19], cancer [20], liver diseases [20, 21], cardiac diseases [22, 23], neurodegenerative diseases [24, 25], and renal research [26].

Although understanding pathophysiology of sepsis is expected to have a marked impact on the development of new effective treatment strategies, underlying molecular mechanisms of renal dysfunction in sepsis are still largely unknown [7]. Furthermore, there are currently no strong biomarkers specifically linked to valid prediction and outcome of sepsisinduced acute kidney failure $[27,28]$ that could guide a prompt tailored therapy. The exact mechanisms involved are still not clear, due to difficulties to obtain histological data or biochemical kidney function marks in the different sepsis phases [9].

The present study investigates changes of protein expression in kidney tissue in a cecal ligature and puncture (CLP) model of rat sepsis during a time-course of 24 or 48 hours after sepsis induction. More specifically, proteomic analysis was performed between kidney tissues of healthy rats and CLP sepsis rats (24 hours or 48 hours, resp.). These findings were analyzed and compared in the context of bioinformatic protein-interaction analyses. Because proteins are vital molecules in normal biological or pathological functions, analysis of all proteins (i.e., the proteome) may clarify the role of specific proteins and possible protein-protein interactions in AKI [29].

\section{Materials and Methods}

2.1. Animal Treatment. Upon approval by the local institutional review board (Regierungspraesidium Karlsruhe, Germany), experiments were performed according to the regulations of the National Institutes of Health Guide for the Use of Laboratory Animals. Male Wistar rats (Charles River Deutschland, Sulzfeld, Germany) were kept under temperature controlled environmental conditions at $22^{\circ} \mathrm{C}$ on a 14 -hour light followed by a 10 -hour dark cycle prior to the experiments and were fed a standard diet (Altromin C1000, Altromin, Lage, Germany) with free access to food and water. Animal treatment was performed as previously published in other trials [13-15].

2.2. Study Groups. A total of 26 rats weighting $330 \pm 10 \mathrm{~g}$ standard deviation (SD) were used for this study. Six rats ware assigned to a sham group without cecal ligature and puncture (CLP, control group). Based on mortality results from our laboratory [13], 20 rats were assigned to the sepsis group receiving CLP. Eight rats died before 24 hours and 12 rats were assigned to two different sepsis groups (euthanasia after 24 and 48 hours, resp.) being used for proteomic analysis.

2.3. Sepsis Model. For the induction of sepsis, the CLP model [30, 31] was used as previously described [13-15]. On the day of surgery, animals were randomly assigned to the defined sepsis or sham group. Rats were anesthetized under spontaneous breathing with sevoflurane (1 MAC) in a gaseous mixture of $30 \%$ oxygen and $70 \%$ nitrous oxide.

After weighing, animals of the sepsis group underwent laparotomy and ligation of the cecum (CLP) just below the ileocecal valve with double punctures (18 gauge needle) at the antimesenterial wall. One $\mathrm{mm}^{3}$ of feces was manually squeezed out of the intestines in each rat. Thereafter, the abdominal wall was closed in two layers.

Rats in the sham group underwent laparotomy with cecum exenteration but without cecal ligation or puncture. For fluid restoration due to anaesthesia, $10 \mathrm{~mL} / \mathrm{kg}$ of $0.9 \%$ $\mathrm{NaCl}$ was injected subcutaneously. In both groups, anaesthesia was terminated, and the rats were allowed to recover. Thereafter, food and water were freely available.

Depending on the group assignment, rats were reanesthetized as described above at the defined time points of the experiments (24 or 48 hours after surgery) and underwent both blood and organ removal after decapitation in deep anaesthesia. After a lateral thoracotomy of both sides the heart was exposed and at least $5 \mathrm{~mL}$ of blood was obtained by direct cardiac puncture for bacterial analysis (blood culture BACTECTM PEDS-bottle, cultivation on blood agar, boiled blood agar, and McConkey media, BD PhoenixTM automated microbiology system, Becton Dickinson Diagnostic Systems, Franklin Lakes, NJ, USA), arterial blood gases, electrolytes, haemoglobin (Bayer Vital Diagnostics, Rapidlab 865, Fernwald, Germany), blood cell count (Advia 60, Bayer Vital Diagnostics, Fernwald, Germany), albumin, and phosphate (bromocresol green, ammonium molybdate, Advia 2400, Bayer Vital Diagnostics, Fernwald, Germany). Physiological markers of rats are depicted in Table 1 . The kidneys were removed as quickly as possible for proteomic analysis, frozen in isopentane prechilled to -40 to $-50^{\circ} \mathrm{C}$, and stored at $-80^{\circ} \mathrm{C}$ for further analysis.

2.4. Sample Preparation. The following techniques and methodologies to identify altered proteins, including samples preparation, 2D-DIGE, and PMF, were performed by TopLab (Martinsried, Germany), being certified ISO 9001:2008. Briefly, the following steps were performed. 
Each frozen kidney was weighed and those from each experimental condition were pooled and grinded with liquid nitrogen in mortar. The tissue powder of the pooled samples was mixed with $4 \mathrm{~mL}$ of lysis buffer [7 $\mathrm{M}$ urea, $2 \mathrm{M}$ thiourea, 4\% CHAPS, $30 \mathrm{mM}$ Tris $\mathrm{pH} 8.5$, Roche complete protease inhibitor cocktail, 1.2\% Pefablock SC protease inhibitor, 1\% Sigma phosphatase inhibitor cocktail 2, and 1\% Sigma phosphatase inhibitor cocktail 3] and transferred into a $15 \mathrm{~mL}$ reaction tube. Cells were lysed and proteins dissolved using vigorous vortexing and sonication with a pulse of $1 \mathrm{~min}$ on ice. For sonication, portions of $\sim 0.8 \mathrm{~mL}$ of each sample were treated with a pulse of $1 \mathrm{~min}$ using a Branson Sonifier ${ }^{\circledR}$ Ultrasonic cell disruptor with an ice chilled thermostat. Samples were vortexed, incubated $5 \mathrm{~min}$ on ice, and centrifuged for $15 \mathrm{~min}$ at $20,000 \times \mathrm{g}$ to pellet debris and insoluble material. The supernatant was taken for further analysis and proteomics.

The protein concentration of samples was determined using a Bradford assay [32]. According to the protein determination results with Bradford assay, $150 \mu \mathrm{g}$ protein of each sample was diluted with labeling buffer [ $30 \mathrm{mM}$ Tris, $\mathrm{pH} 8.5$; $7 \mathrm{M}$ urea; $2 \mathrm{M}$ thiourea; 4\% CHAPS; Roche complete protease inhibitor cocktail; Pefablock SC protease inhibitor] to a final volume of $450 \mu \mathrm{L}$. The samples were rebuffered with labeling buffer using Vivaspin 500 ultrafiltration devices with a cutoff of $5 \mathrm{kDa}$. After volume reduction samples were present in $100 \mu \mathrm{L}$ labeling buffer at last with a protein concentration of $5 \mathrm{mg} / \mathrm{mL}$.

2.5. DIGE Labeling. $65 \mu \mathrm{g}$ of the samples control and sepsis $48 \mathrm{~h}$ treatment was labeled with $\mathrm{Cy} 3$ and $65 \mu \mathrm{g}$ of the samples control and sepsis $24 \mathrm{~h}$ treatment was labeled with Cy5. Additionally, $50 \mu \mathrm{g}$ of each sample was pooled as the internal standard sample (Pool-A) and $65 \mu \mathrm{g}(13 \mu \mathrm{L})$ of this mixture was used for each labeling reaction with Cy2. For each labeling reaction with Cy2, Cy3, and Cy5 $65 \mu$ g protein $(13 \mu \mathrm{L})$ was applied to $400 \mathrm{pmol}$ CyDye. The reactions were performed on ice for $30 \mathrm{~min}$ and stopped by adding lysine and incubating for another $10 \mathrm{~min}$. Labeling was performed according to the manufacturer's protocol (FluoProbes/InterChim: 2-D DIGE Cy5/3/2 Labeling kit). The labeling chemistry is based on minimal labeling of lysine residues of the proteins, with one lysine residue labeled per protein on average [33].

After labeling, reactions to run in the same 2D-DIGE gel were pooled. The final volume of each sample was adjusted to $100 \mu \mathrm{L}$ with lysis buffer B [7 M urea; $2 \mathrm{M}$ thiourea; 4\% CHAPS; Roche complete protease inhibitor cocktail; Pefablock SC protease inhibitor] and samples were supplemented with $2 \%$ Servalyte and $1 \%$ DTT. Finally, $350 \mu \mathrm{L}$ of rehydration buffer [6 $\mathrm{M}$ urea; $2 \mathrm{M}$ thiourea; $2 \%$ CHAPS; $1 \%$ DTT; 1 v/v\% Servalyte 3-10 Iso-Dalt for 2D, Roche complete protease inhibitor cocktail; Pefablock SC protease inhibitor] was added to each sample.

2.6. 2D-DIGE. For the 2D-DIGE experiment, samples were loaded directly after labeling onto two $24 \mathrm{~cm}$ IPG strips $\mathrm{pH}$ 3-10 NL from Serva ( $T=4 \%, C=2.7 \%)$ using passive ingel-rehydration for sample application. Therefore, the IPG strips were rehydrated with $450 \mu \mathrm{L}$ sample for 16 hours at room temperature. Isoelectric focusing (IEF) was performed for $100 \mathrm{kVh}$ in total. All steps were limited with $75 \mu \mathrm{A}$ per strip and performed at $20^{\circ} \mathrm{C}$. The applied instrument was an IEF 100 focusing unit from Hoefer.

Protein separation in the second dimension was carried out on precast 2D HPETM gels $(T=12.5 \%, C=2.7 \%)$ with a SDS-GLYCIN-TRIS buffer system overnight (SDS, sodium dodecyl sulfate). A molecular weight standard, commercially available from Serva, was previously labeled with Cy2. The standard comprising masses corresponding to $97,67,45,29$, $21,12.5$, and $6.5 \mathrm{kDa}$. respectively, was applied to the gel and positioned next to the IPG strips. The two 2D-DIGE gels were run in parallel (HPETM FlatTop Tower from Serva with a Multi-TempIII Thermostatic Circulator and a HPE-Power Supply 1500).

2.7. Image Analysis and Spot Significance. To visualize the labeled and separated proteins after electrophoresis, the 2DDIGE gels were scanned at a resolution of $100 \mu \mathrm{m}$ with a Typhoon FLA 9500 (GE Healthcare).

For image analysis, scan files of the 2D-DIGE gels were loaded into DeCyder 2D software (GE Healthcare, version 7.2). Spots were detected with an estimate of 5,000 spots for the 2D-DIGE gel. Subsequently, a detection area excluding the region of strip application, molecular weight marker, and running front was defined. Spots with a volume below 100,000 were defined to be background. Stained crumbs originated from the Dyes were eliminated by excluding spots with an area below 350. False positive spots, for example, produced by dye artefacts within the gel were removed manually. After the editing the gels were normalized towards the Cy2 channel (internal standard).

2.8. Statistical Analysis and Data Handling. Spot IDs were allocated to each spot detected and matched in the two 2DDIGE gels. An average ratio of spot volumes from different samples was calculated for each spot ID. In case a value of 3.0 was calculated for the average ratio, this means the spot volume did increase three times compared to the reference; an average ratio of -3.0 means a threefold decrease. Unchanged spot volumes have ideally an average ratio of 1.0 .

The values of 2-fold SD (twice standard deviation) and the corresponding thresholds of spot volumes were calculated and documented (Table 1). Using filter settings for these threshold values differences in the spot volumes between two samples were identified.

Subsequent image analysis with DeCyder software was performed to determine differences between the samples. The calculation was based on spot volumes after normalization with the signals from the internal standard sample. Based on the total spot number of detected spots and the standard deviation, DeCyder 2D software calculates the threshold of regulation. In case a spot volume of a certain spot in one sample equates the $x$-fold of the spot volume in a second sample, this spot is regulated if $x$ is above the threshold of regulation $(x>+$ threshold or $x<-$ threshold). 
TABLE 1: Physiological markers of rats in both groups analyzed. Data is presented as means. Fishers' exact test was used for statistical analysis. n.s.: not significant; bold-type numbers are significantly different from control.

\begin{tabular}{|c|c|c|c|c|}
\hline Marker & Control/sham group & 24-hour sepsis group & 48-hour sepsis group & $P$ value \\
\hline CRP, c-reactive protein $[\mathrm{ng} / \mu \mathrm{L}]$ & 2.0 & 2.0 & 2.0 & n.s. \\
\hline WBC, white blood cells $[/ \mu \mathrm{L}]$ & 3.2 & 2.3 & 2.8 & $P<0.05$ \\
\hline Ery, erythrocytes & 6.1 & 6.6 & 6.6 & n.s. \\
\hline Hb, haemoglobin level & 13.3 & 13.2 & 13.9 & n.s. \\
\hline Hk, hematocrit [\%] & 0.37 & 0.38 & 0.40 & n.s. \\
\hline $\mathrm{MCV}$, mean corpuscular volume & 59 & 58 & 57 & n.s. \\
\hline $\begin{array}{l}\mathrm{MCH} \text {, mean corpuscular } \\
\text { haemoglobin }\end{array}$ & 22 & 21 & 20 & n.s. \\
\hline PLT, platelets $\left[10^{3} / \mu \mathrm{L}\right]$ & 818 & 400 & 456 & $P<0.05$ \\
\hline
\end{tabular}

Using DeCyder 2D software, the normalized spots were matched and the gel images were grouped according to the samples loaded on the gels. Comparison of the samples was performed using the 2 SD threshold combined with student's $t$-test. Differences between the samples were defined to be significant if the average ratio of the spot volumes was above or below the threshold for $2 \mathrm{SD}$ and the spot did pass the students $t$-test $(P=0.01)$.

2.9. Protein Identification. We chose to compare the protein expressions between the samples taken 24 and 48 hours after completion, as well as between sepsis treated samples (grouping the gels of sepsis $24 \mathrm{~h}$ treatment and sepsis $48 \mathrm{~h}$ treatment) and control sample.

Specific protein spots were identified with peptide mass fingerprinting (PMF) using tryptic in-gel digestion and MALDI-TOF-MS. The spots were manually excised and destained using an acetonitrile containing buffer. Ingel digestion was performed overnight with $0.006-0.02 \mu \mathrm{g}$ trypsin (Serva, sequencing grade, cat. number 37283) in $10 \mathrm{mM} \mathrm{NH}_{4} \mathrm{HCO}_{3}$ buffer. Peptides were cocrystallized with matrix $(10 \mathrm{mg} / \mathrm{mL} \alpha$-cyanohydroxy-cinnamic acid) onto the MALDI target. Measurement was performed with a 4800 MALDI-TOF/TOF Analyzer (AB Sciex, Framingham, MA, USA) using positive reflector mode (detection range $\mathrm{m} / \mathrm{z}$ 700-4500).

Raw data were processed with GPS Explorer software (AB Sciex, Framingham, MA, USA). All spectra were externally calibrated using a peptide calibration standard. The measured monoisotopic peptide masses were compared to all Rattus sequences of the SwissProt database (7,928 rat sequences, updated December 2014) using the software MASCOT (Matrix Science, London, UK).

In order to obtain enough material for analysis with mass spectrometry, a preparative $2 \mathrm{D}$-gel loaded with a mixture of control and sepsis samples of $24 \mathrm{~h}$ and $48 \mathrm{~h}$ treatment was produced and stained with colloidal Coomassie.

2.10. Bioinformatic Network Analysis and Protein Functions Analysis. To identify relevant pathways involved and to describe the interactions and functions of our findings, STRING 10 (Search Tool for Retrieval of Interacting
Genes/Proteins, http://string-db.org/), GeneMANIA (http:// www.genemania.org/), the KEGG database (Kyoto Encyclopedia of Genes and Genomes, http://www.genome.jp/ kegg/), and Pathway Commons (http://www.pathwaycommons.org/) were used.

STRING 10 is a web-server database that provides prediction and information about functional interactions between proteins in form of networks $[34,35]$. Predictions are based on systematic genome comparisons that consider conserved genomic neighborhood, gene fusion events, cooccurrence of genes across genomes, and coexpression in other species [36]. Furthermore, published indexed articles, experimental data, and knowledge of manually curated databases are taken into account for the prediction [34].

To assess the likelihood of the prediction (level of confidence), STRING 10 matches and calibrates findings with KEGG pathways database knowledge as a reference [34, 36]. At the end of these events, a score indicates the level of confidence, with the highest confidence set at 0.900, high confidence at 0.700 , medium confidence at 0.400 , and low confidence at 0.150 . This final score results by combination of the scores regarding the other parameters considered (genomic neighborhood, gene fusion, etc.).

Search terms are typed in the box of the web tool, one per line, and the depicted pathway can be adjusted (managing some parameters as level of confidence, number of interactions, etc.) to have the desired view of the interactions and information. Similarly to STRING, GeneMANIA is a tool that helps to predict interactions and function of list of genes in form of network and, when available, of pathway $[37,38]$. Algorithms and data sources are different, but the major difference with STRING is that GeneMANIA gives the possibility of better customizing the network, allowing the choice of data sources or highlighting specific functions, with a more comfortable graphic experience [37]. It is developed and continually updated by the University of Toronto and is funded by the Ontario Ministry of Research and Innovation. GeneMANIA knowledge is based on data from large databases, which comprehend Gene Expression Omnibus, BioGRID, EMBL-EBI, Pfam, Ensembl, Mouse Genome Informatics, the National Center for Biotechnology Information, InParanoid, and Pathway Commons [37, 38]. As 
these software programs use different algorithms, we chose to perform the bioinformatics analysis with all of them in order to retrieve the highest number of predicted interactions, maintaining an acceptable level of confidence (0.400). KEGG, one of the largest existing library of genes and network [39], is organized in three databases: one for the genes of all completed genomes (GENES database); one for functional information, as cellular process, depicted as manually curated functional pathways (PATHWAYS database); and one for enzymes and enzymatic reactions (LIGAND database) [39].

Pathway Commons (PCViz) is a collection of publicly available pathway information from multiple organisms [40]. It provides researchers with convenient access to a comprehensive collection of biological pathways from multiple sources represented in a common language for gene and metabolic pathway analysis. Access is via a web portal for query and download. Pathways can include biochemical reactions, complex assembly, transport and catalysis events, physical interactions involving proteins, DNA, RNA, small molecules and complexes, gene regulation events, and genetic interactions involving genes.

Pathway Commons integrates a number of pathway and molecular interaction databases supporting BioPAX and PSI-MI formats into one large BioPAX model, which can be queried using the web API. This API can be used by computational biologists to download custom subsets of pathway data for analysis or can be used to incorporate powerful biological pathway and network information retrieval and query functionality into websites and software.

2.11. Western Blot Analysis. For the 1D SDS PAGE analysis, the specific samples were diluted to a concentration of $10 \mu \mathrm{g} / \mu \mathrm{L}$ with HPLC water. Subsequently, a further dilution step to $1.5 \mu \mathrm{g} / \mu \mathrm{L}$ with HPLC water was performed. To each of the six diluted samples an equal volume of $3 x$ SDS sample buffer [30\% glycerol; $187.5 \mathrm{mM}$ Tris pH 6.8; 6\% SDS, 3\% DTT] was added. Samples were boiled for $10 \mathrm{~min}$ at $90^{\circ} \mathrm{C}$.

For protein separation a precast Tris-Glycine Gel $T(\%)$ 4-20 from Serva (SERVAGel ${ }^{\mathrm{TM}}$ TG 4-20) was used. A total protein amount of $100 \mu \mathrm{g}$ and $15 \mu \mathrm{g}$ of each of the three samples was loaded, by applying $20 \mu \mathrm{L}$ of the prepared dilutions. To estimate the molecular weight of the proteins and to check transfer efficiency $5 \mu \mathrm{L}$ of a prestained marker (Serva Triple Color protein standard III) and twice $5 \mu \mathrm{L}$ of an unstained protein marker (Protein test mixture 6, Serva) were also loaded. Lanes without protein load were filled with $1 \mathrm{x}$ sample buffer instead to ensure an even gel run.

The gel run was started at low power for $10 \mathrm{~min}$ a $10 \mathrm{~mA} /$ gel. The main separation took place at $25 \mathrm{~mA} /$ gel with the current limited at $500 \mathrm{~V}$. After $110 \mathrm{~min}(284 \mathrm{Vh})$ the dye front was about $5 \mathrm{~mm}$ above the rear of the gel and the gel run was stopped.

In order to transfer the proteins from the SDS gel onto a polyvinylidene fluoride (PVDF) membrane a Trans-Blot ${ }^{\circledR}$ SD Semi-Dry Electrophoretic Transfer Cell from BioRad and a discontinuous buffer system according to Khyse-Andersen was used. Therefore three sheets of blotting paper (Schleicher \& Schuell) and the gel were incubated for 5-10 $\mathrm{min}$ in cathodic transfer buffer $(0.04 \mathrm{M}$ 6-aminohexanoic acid (epsilon-aminocaproic acid), 20\% isopropanol, and 0.01\% SDS). One further sheet of blotting paper was incubated in anodic buffer I ( $0.3 \mathrm{M}$ Tris, $20 \%$ isopropanol) and three sheets were incubated in anodic buffer II (0.025 M Tris, $20 \%$ isopropanol). The PVDF membrane was activated for $10 \mathrm{~s}$ with methanol and then incubated in cathodic transfer buffer.

A glass pipette was carefully used as a rolling pin when assembling the blot to remove air bubbles from the sandwich. For the transfer $5 \mathrm{~mA}$ per $\mathrm{cm}^{2}$ membrane was applied. The transfer was performed overnight at $4^{\circ} \mathrm{C}$. Protein transfer was checked by staining the PVDF membrane with Ponceau S and the blotted gel was additionally stained with colloidal Coomassie to visualize the amount of proteins remaining in the gel after transfer.

For blocking $10 \%$ BSA in TBS-T [ $20 \mathrm{mM}$ Tris $\mathrm{pH}$ 7.6; $155 \mathrm{mM} \mathrm{NaCl} ; 0.05 \%$ Triton-X 100; $10 \%$ BSA] was used and the membrane was incubated for $1 \mathrm{~h}$ at RT. Incubation with primary antibody (Anti-COX5B antibody [16H12H9] ab110263) was performed in TBS-T/2\% BSA [20 mM Tris $\mathrm{pH}$ 7.6; $155 \mathrm{mM} \mathrm{NaCl} ; 0.05 \%$ Triton-X 100; $2 \% \mathrm{BSA}$ ] for $42 \mathrm{~h}$ at $+4^{\circ} \mathrm{C}$. The antibody was diluted to $1 \mu \mathrm{g} / \mathrm{mL}$. Subsequently, the membrane was washed three times for $10 \mathrm{~min}$ at RT with TBS-T [20 mM Tris pH 7.6; $155 \mathrm{mM} \mathrm{NaCl}$; 0.05\% Triton-X 100]. The secondary antibody (HRP-conjugated Anti-Mouse IgG produced in rabbit, Sigma-Aldrich A9044) was diluted $1: 100,000$ in TBS-T/2\% BSA and applied for $1 \mathrm{~h}$ at RT. Thereafter the membrane was washed three times for $10 \mathrm{~min}$ at RT with TBS-T and once for a few minutes with deionized water. The horseradish-peroxidase-coupled antibody (HRP) was visualized using an enhanced chemiluminescence (ECL) substrate kit from Thermo Fisher (Super Signal West Femto) and the signals were detected with a charge-coupled device (CCD) camera system.

After signal acquisition the membrane was frozen at $-20^{\circ} \mathrm{C}$ until further processing. The next day, the membrane was thawed and stripped from the previously applied antibodies by incubation for 30 seconds with prewarmed stripping buffer $[62.5 \mathrm{mM}$ Tris $\mathrm{HCl} \mathrm{pH} 6.8,2 \%$ SDS, and $100 \mathrm{mM}$ DTT]. Subsequently the membrane was extensively washed with water and blocked with $10 \%$ BSA in TBS-T [20 mM Tris pH 7.6; $155 \mathrm{mM} \mathrm{NaCl}$; 0.05\% Triton-X 100; 10\% $\mathrm{BSA}]$ for $1 \mathrm{~h}$ at room temperature.

As control and to check for equal protein load, antialpha tubulin antibody was used as an internal loading control. Incubation with primary antibody (anti-alpha tubulin antibody [EP1332Y], Microtubule Marker, ab52866) was performed in TBS-T/2\% BSA [20 mM Tris pH 7.6; $155 \mathrm{mM}$ $\mathrm{NaCl} ; 0.05 \%$ Triton-X 100; $2 \% \mathrm{BSA}]$ for $42 \mathrm{~h}$ at $+4^{\circ} \mathrm{C}$. The antibody was diluted $1: 50,000$. Subsequently, the membrane was washed three times for $10 \mathrm{~min}$ at RT with TBS-T [20 mM Tris pH 7.6; $155 \mathrm{mM} \mathrm{NaCl;0.05 \%} \mathrm{Triton-X} \mathrm{100].}$ The secondary antibody (HRP-conjugated anti-rabbit IgG, Molecular Probes, G21234) was diluted 1: 7,000 in TBS-T/2\% BSA and applied for $1 \mathrm{~h}$ at RT. Thereafter the membrane was washed three times for $10 \mathrm{~min}$ at RT with TBS-T and once for a few minutes with deionized water. The HRP-coupled 


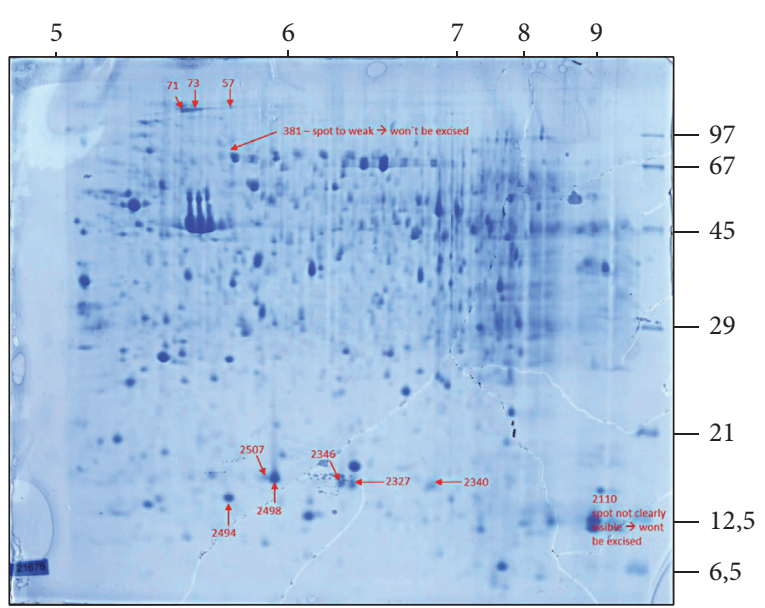

(a)

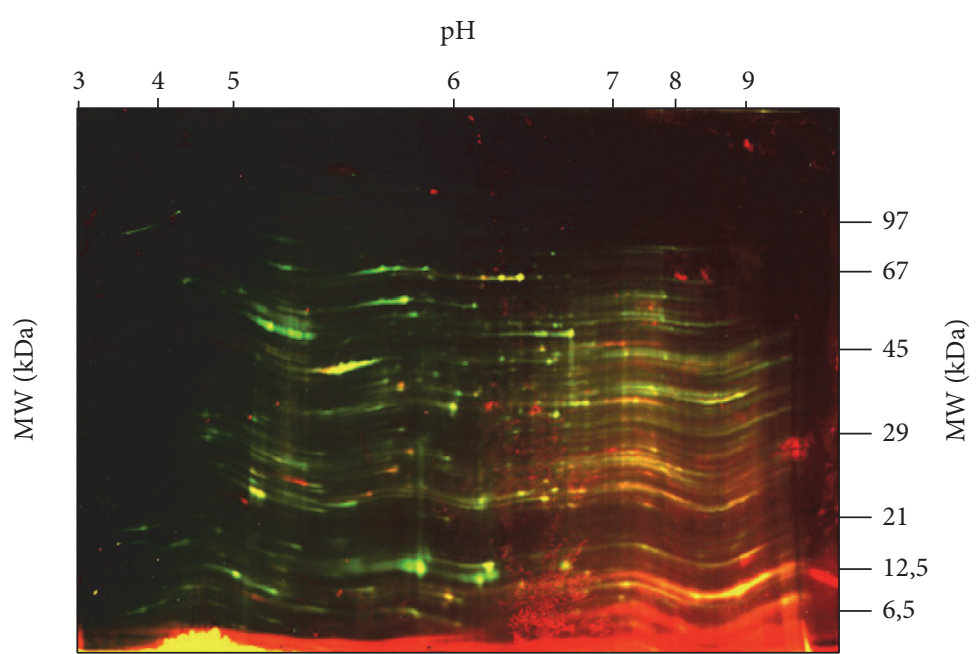

(b)

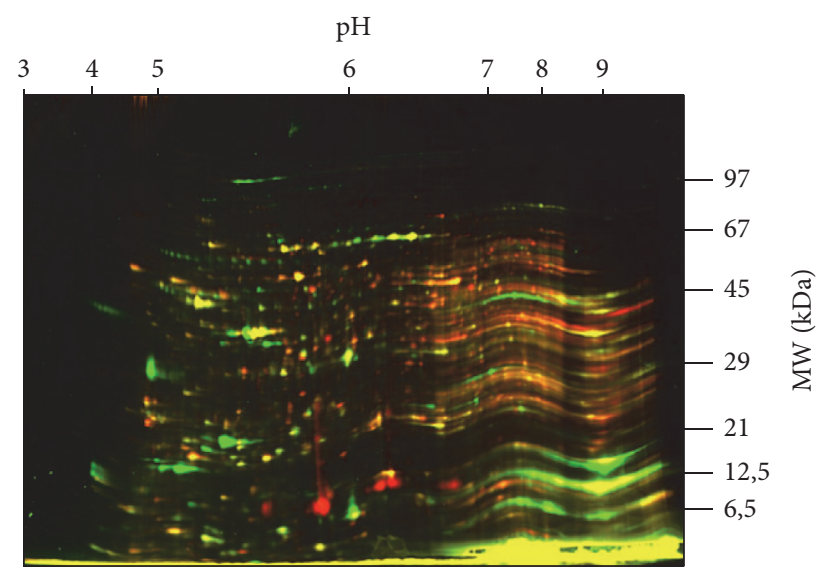

(c)

Figure 1: (a) Preparative 2D-Gel (Coomassie blue) of control and sepsis samples. Threshold of regulation is 2 SD (standard deviation) and $t$-test value $P<0.01$. Spots \#381 and \#2110 have not been analyzed (Table 2) since they were too weak or not visible for excision. Other spots are marked with arrows and numbers. Alteration of the spots is presented in Table 3. The gel is a sample gel with proteins of the 24 hours' group. (b) Cy3 and Cy5 images of the gels. Cy5: red color = sepsis $24 \mathrm{~h}$ group. Cy3: green color = control group. The gel shows proteins of the control group and 24 hours group. (c) Cy3 and Cy5 images of the gels. Cy5: red color $=$ control group. Cy3: green color $=48 \mathrm{~h}$ sepsis group. The gel shows proteins of the control group and 48 hours' group.

antibody was visualized using an ECL substrate kit from Thermo Fisher (Super Signal West Femto) and the signals were detected with a CCD camera system.

\section{Results}

$N=26$ male Wistar rats were used for the present study. $N=6$ rats were treated with sham surgery and served as controls (healthy rats), and $N=20$ underwent CLP for sepsis induction. Of these 20 rats, $N=8$ died before the experiments and $N=6$ were sacrificed $24 \mathrm{~h}$ after CLP (intermediate sepsis) and $N=6$ were sacrificed $48 \mathrm{~h}$ after CLP (late sepsis). White blood cell (WBC; $3.2 * 10^{9} / \mu \mathrm{L}$ versus $2.3 *$ $10^{9} / \mu \mathrm{L}$ and $\left.2.8 * 10^{9} / \mu \mathrm{L} ; P<0.05\right)$ count and platelet count (PLT; $818 * 10^{3} / \mu \mathrm{L}$ versus $400 * 10^{3} / \mu \mathrm{L}$ and $456 * 10^{3} / \mu \mathrm{L}$ ) differed significantly between the sepsis and control group (Table 1).

3.1. 2D-DIGE Analysis. With the present technique, more than 1.500 different spots were identified on the gels using the 2D-DIGE analysis with DeCyder 2D. After specific calculations by DeCyder 2D, a total of 12 spots was different expressed in the groups/gels analyzed (Figures 1(a)-1(c)).

Seven protein spots were discovered to be differently present between $24 \mathrm{~h}$ sepsis and $48 \mathrm{~h}$ sepsis. $N=5$ of these spots were higher and abundant in the $24 \mathrm{~h}$ sample sepsis; the other two protein spots were higher and abundant in the $48 \mathrm{~h}$ sample sepsis (Table 2). From analysis between sample and the mixture of samples from $24 \mathrm{~h}$ sepsis and $48 \mathrm{~h}$ sepsis, $N=5$ different protein spots, all of them in higher abundance in the control sample, were found (Table 2). 


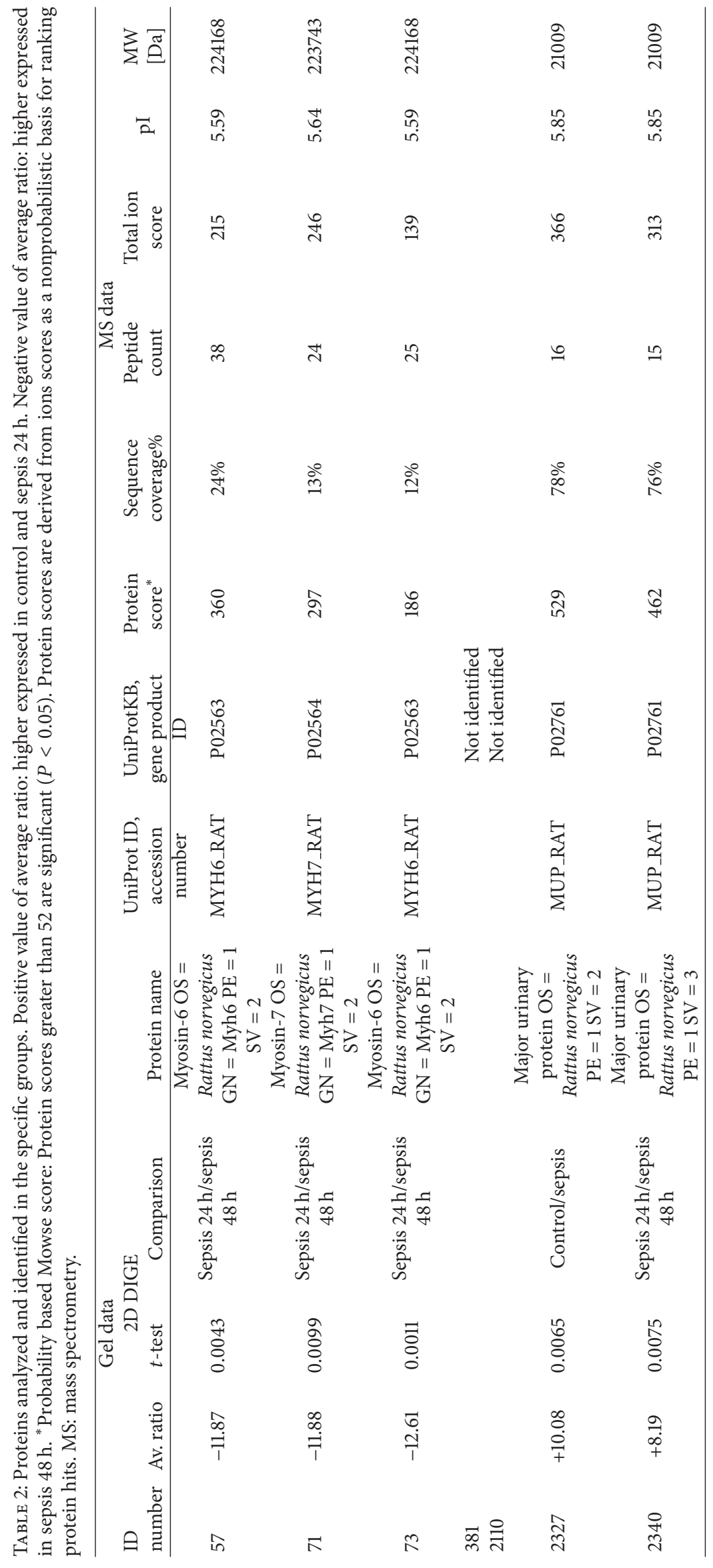




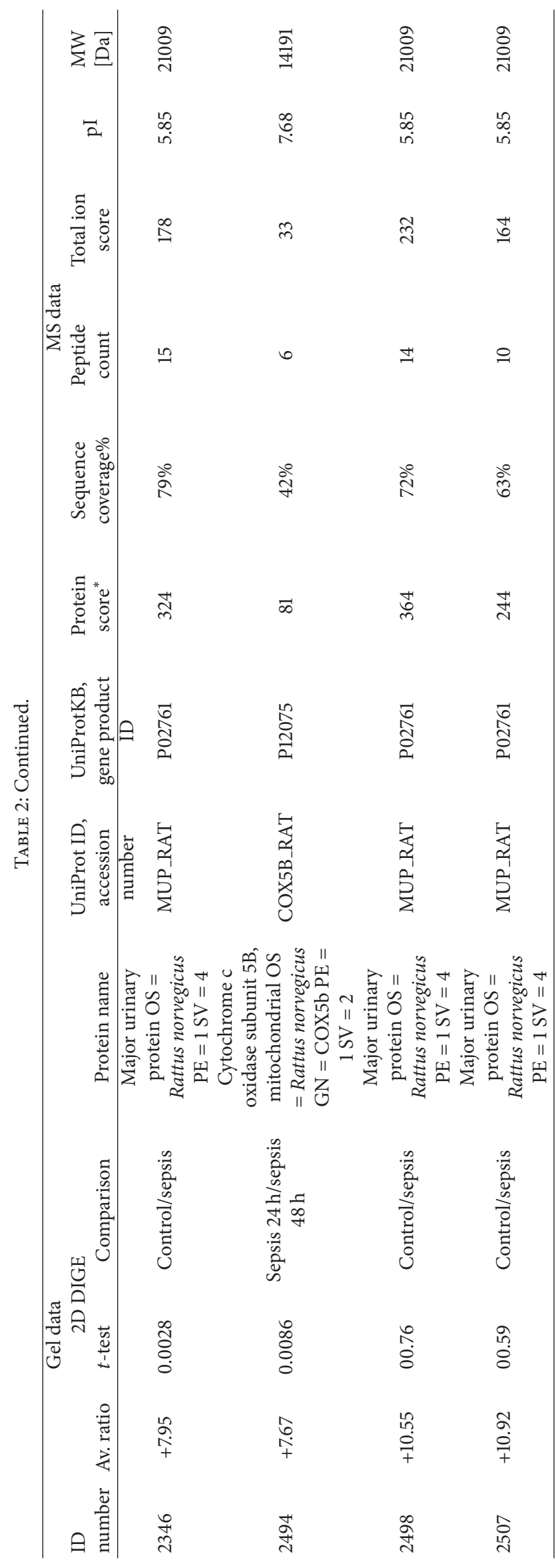


TABLE 3: Identified and significantly regulated protein spots and changes at 24 hours and 48 hours after sepsis induction as compared to control. $(\uparrow)=$ upregulated protein; $\uparrow=$ highly upregulated protein; $(\downarrow)=$ downregulated protein; $\downarrow$ = highly downregulated protein.

\begin{tabular}{|c|c|c|c|c|}
\hline Protein abbreviation & Protein name & Spot number & 24 hours versus control & 48 hours versus control \\
\hline \multirow{2}{*}{ MYH6 } & \multirow{2}{*}{ Myosin-6 } & 57 & $(\uparrow)$ & $\uparrow$ \\
\hline & & 73 & $(\uparrow)$ & $\uparrow$ \\
\hline MYH7 & Myosin-7 & 71 & $(\uparrow)$ & $\uparrow$ \\
\hline COX5B & $\begin{array}{c}\text { Cytochrome c oxidase } \\
\text { subunit } 5 \mathrm{~B}, \\
\text { mitochondrial }\end{array}$ & 2494 & $(\uparrow)$ & $\uparrow$ \\
\hline \multirow{5}{*}{ MUP5 } & \multirow{5}{*}{ Major urinary protein } & 2327 & $\downarrow$ & $\downarrow$ \\
\hline & & 2340 & $(\downarrow)$ & $\downarrow$ \\
\hline & & 2346 & $\downarrow$ & $\downarrow$ \\
\hline & & 2498 & $\downarrow$ & $\downarrow$ \\
\hline & & 2507 & $\downarrow$ & $\downarrow$ \\
\hline
\end{tabular}

3.2. Preparative 2D-Gel Analysis. Subsequent analysis with DeCyder 2D of the preparative 2D-gel analysis (grouping the samples of the three groups) found 11 protein spots corresponding to that found with the previous 2-DIGE analyses (Table 2). Of these, two protein spots, ID 381 and ID 2110, belonging to sepsis samples, were not clearly visible and, therefore, were not excised for protein identification. Hence, a total of 9 spots, 4 higher and abundant in control sample, 3 higher and abundant in $48 \mathrm{~h}$ sepsis, and 2 higher and abundant in $24 \mathrm{~h}$ sepsis, were considered for protein identification by PMF and were matched through MASCOT software with SwissProt database for the identification.

3.3. Protein Identification. In the four spots found higher and abundant in the control sample (ID 2346, ID 2507, ID 2327, and ID 2498), major urinary protein ("MUP5" for the STRING database) was identified. MUP5 was detected also in spot ID 2494 that was found higher and abundant in $24 \mathrm{~h}$ sepsis. In the other spot overpresent in $24 \mathrm{~h}$ sepsis, ID 2494, cytochrome c oxidase subunit B (“COX5B") was recognized. In three spots found higher and abundant in $48 \mathrm{~h}$ sepsis, myosin-6 ("MYH6") from spots ID 57 and ID 73 and myosin7 ("MYH7”) from spot ID 71 were identified. Table 3 shows alterations of protein expression in the specific groups (24 hours or 48 hours) as compared to control. For the five MUP5 spots and COX5B, expression was downregulated at both time points and for MYH6 and MYH7 it was upregulated as compared to control (Figure 3 and Table 3 ).

3.4. Bioinformatic Networks Analyses. STRING 10, GeneMANIA, and PCViz were used for separate network analysis. Using the STRING software, COX5B and MYH6 were found to belong to two separated networks but linked with a level of confidence of 0.508 through cytochrome $c$ oxidase subunit 6 A2 (COX6A2) and actinin alpha 2 (Actn2) (Figure 3, Tables 3 and 4). MUP5 does not present any connection with these networks (Figure 3). COX5B is likely functionally linked to the others subunits of cytochrome c oxidase, NADH dehydrogenase, and ATP synthase, all the connections with a very high level of confidence $>0.990$ (Figure 3 ).
Myosins 6 and 7 were found to be strongly linked to the other proteins of the muscle contraction (troponin I, actin, tropomyosin alpha-1, and alpha-4 chain), all with a level of confidence $>0,960$ (Figure 3).

Using GeneMANIA and PCViz for analysis, significant correlation of the identified proteins with other network proteins was found. MYH6 and MYH7 were linked especially to other myosin and contractility proteins (Figures 4 and 5). COX5B was found to be linked to 13 other network proteins (Figure 4) as well as to a human cytochrome c protein (CYCS, Figure 6).

3.5. Course of Sepsis: 24 versus 48 Hours after CLP. As compared to the early phase of sepsis (24 hours after CLP), MYH6 (avg. ratio -11.87 and -12.61) and MYH7 (avg. ratio -11.88) were significantly overexpressed in the late phase of sepsis ( 48 hours after CLP, Table 2). However, MUP (avg. ratio +8.19 ) and COX5B (avg. ratio +7.67) were less expressed in the late phase of sepsis (Table 2). Localization of COX5B is mainly from the mitochondrion or intercellular space (Figure 7).

3.6. Pathways and Signaling Cascades. Using the pathway analysis tool by http://www.genecards.org/, several pathways were identified to be associated with COX5B. Besides respiratory electron transport, oxidative phosphorylation (KEGG data base), and electron transport chain (wiki pathways data base) were most important (Table 4).

3.7. Western Blot Analysis and Confirmation of Expression. The protein spot ID2494 (COX5B) was found in the previous 2D DIGE experiment to be significantly lower expressed in the sample sepsis $48 \mathrm{~h}$ treatment compared to the samples sepsis $24 \mathrm{~h}$ treatment and control. Between the samples sepsis $24 \mathrm{~h}$ treatment and control, this protein spot was not significantly differentially expressed.

Western Blot analysis of the three samples (separated with 1D SDS PAGE and transferred onto PVDF) was performed to check whether the protein COX5B is differentially expressed. After incubation with the anti-COX5B antibody a distinct band at about $12 \mathrm{kDa}$ was detected per lane (Figure 2(b)). 


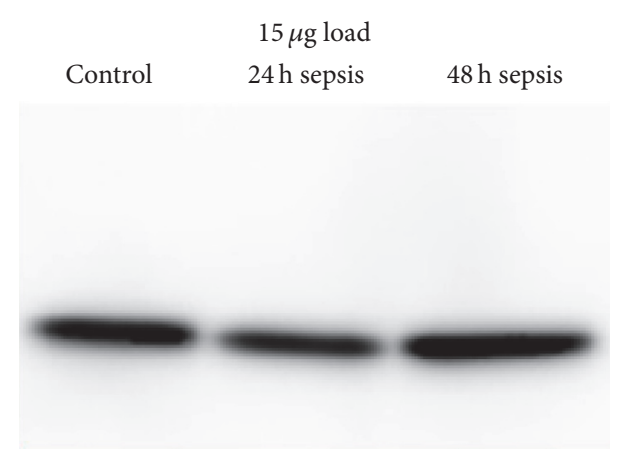

(a) Anti-alpha tubulin

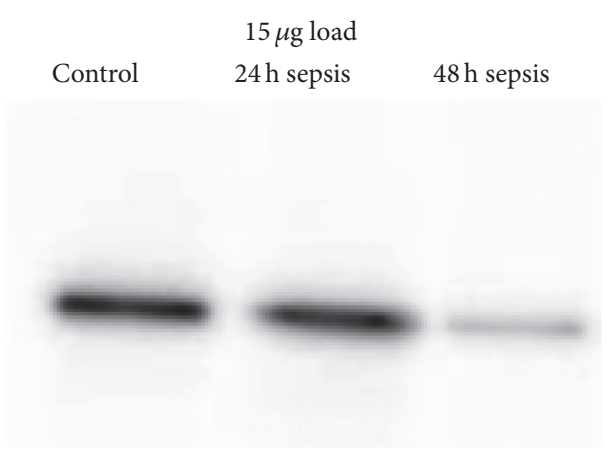

(b) Anti-COX5B

FIGURE 2: Enhanced chemiluminescence (ECL) signal of Western Blot analysis of anti-alpha tubulin (a) which was used as control and of anti-COX5B (b). The anti-tubulin band is located at $55 \mathrm{kDa}$ and the anti-COX5B band is located at $11 \mathrm{kDa}$. For analysis, $15 \mu \mathrm{g}$ load each was used.

No cross-reactions or background signals were observed. Corresponding to the SDS gel analysis, Western Blot analysis also showed a decreased expression of COX5B at 48 hours after sepsis.

As a loading control, the membrane was subsequently incubated with anti-alpha tubulin antibody. A distinct band at about $55 \mathrm{kDa}$ was detected (Figure 2(a)). Following this, the anti-COX5B antibody still gave a clear signal.

The image of the PVDF membrane after transfer and Ponceau $S$ total protein stain showed an even transfer and only slightly different protein load for the three samples as identified by anti-alpha tubulin analysis (Figure 2(a)).

\section{Discussion}

Our findings show differences in expression of several proteins in the rat kidney during intermediate as well as late stage sepsis. Of these proteins, COX5B in particular is of high interest and linked to mitochondrial function and cellular energy production [41]. During the course of sepsis, COX5B was found to be less expressed by both MALDI-TOF and Western Blot analysis in the late phase (i.e., after 48 hours) as compared to the early phase of sepsis.

Proteomics has, during the last decade, increasingly been applied to identify and quantify mitochondrial proteins related to cellular perturbations [12]. So far, several different pathophysiological mechanisms have been proposed for sepsis-induced AKI: vasodilation-induced glomerular hypoperfusion, dysregulated circulation within the peritubular capillary network, inflammatory reactions by systemic cytokine storm or local cytokine production, and tubular dysfunction induced by oxidative stress [2].

4.1. CLP Model and Proteomics. There are still two fundamental problems inherently associated with studies of renal responses to sepsis. First, difficult access to the renal tissue and the associated ethical issues make the human research into cellular and molecular biology in critically ill patients with sepsis almost unfeasible [7]. Second, the process of AKI in sepsis involves a complex of multiple dynamically interacting factors and it is clear that both sepsis and septic organ dysfunction are not caused by a single mechanism [7]. Therefore, experimental studies involving animal models are fundamental to better define and characterize the pathophysiological phases of AKI [9].

We chose CLP model for sepsis because it is widely accepted as one of the most close to the pathophysiologic course of sepsis patient [42], it is easily feasible in small animals [30], and it allows a suitable representation of gramnegative sepsis [30]. The decision to analyze samples after 24 and $48 \mathrm{~h}$ reflects the evidence that clinical and laboratory signs of sepsis become more conspicuous at $24 \mathrm{~h}[13,30]$, going from a hyperdynamic state (after $12 \mathrm{~h}$ ) to a progressive hypodynamic phase (after 16-24h) or late stage (48h) [30, 43-45].

4.2. Course of Sepsis: 24 versus 48 Hours after CLP. Figure 8 shows alterations in expression of the proteins analyzed (Figure 8). The higher abundance of MUP5 in control samples and in intermediate compared to late sepsis samples could suggest a kind of progressive downregulation of this protein with the development of the kidney injury. COX5b also seems to undergo a possible downregulation from intermediate to late sepsis and was confirmed by the Western Blot analysis. MYH6 and MYH7 appear to be the only upregulated proteins during the late stage of sepsis-induced kidney injury.

Cytochrome c oxidase (COX, Complex IV) is a mitochondrial electron transport chain enzyme that resides in the mitochondrial inner membrane, and its activity is required to generate the proton motive force that drives downstream ATP synthesis (Figure 7) [46]. It is one of the mitochondrial isoforms of cytochrome c oxidase, that is, the Complex IV of the mitochondrial respiratory chain (Table 6). COX5B is involved in the final step of the oxidative phosphorylation, with the production of $\mathrm{H}_{2} \mathrm{O}$, and the maintenance of the electrochemical gradient needed to produce ATP. It has been shown that COX5B is implicated in the production of reactive oxygen species (ROS) and nitric oxide (NO) in hypoxic or anoxic conditions in both mammalian and yeast cells [4750]. ROS can lead to mitochondrial dysfunction, and this 


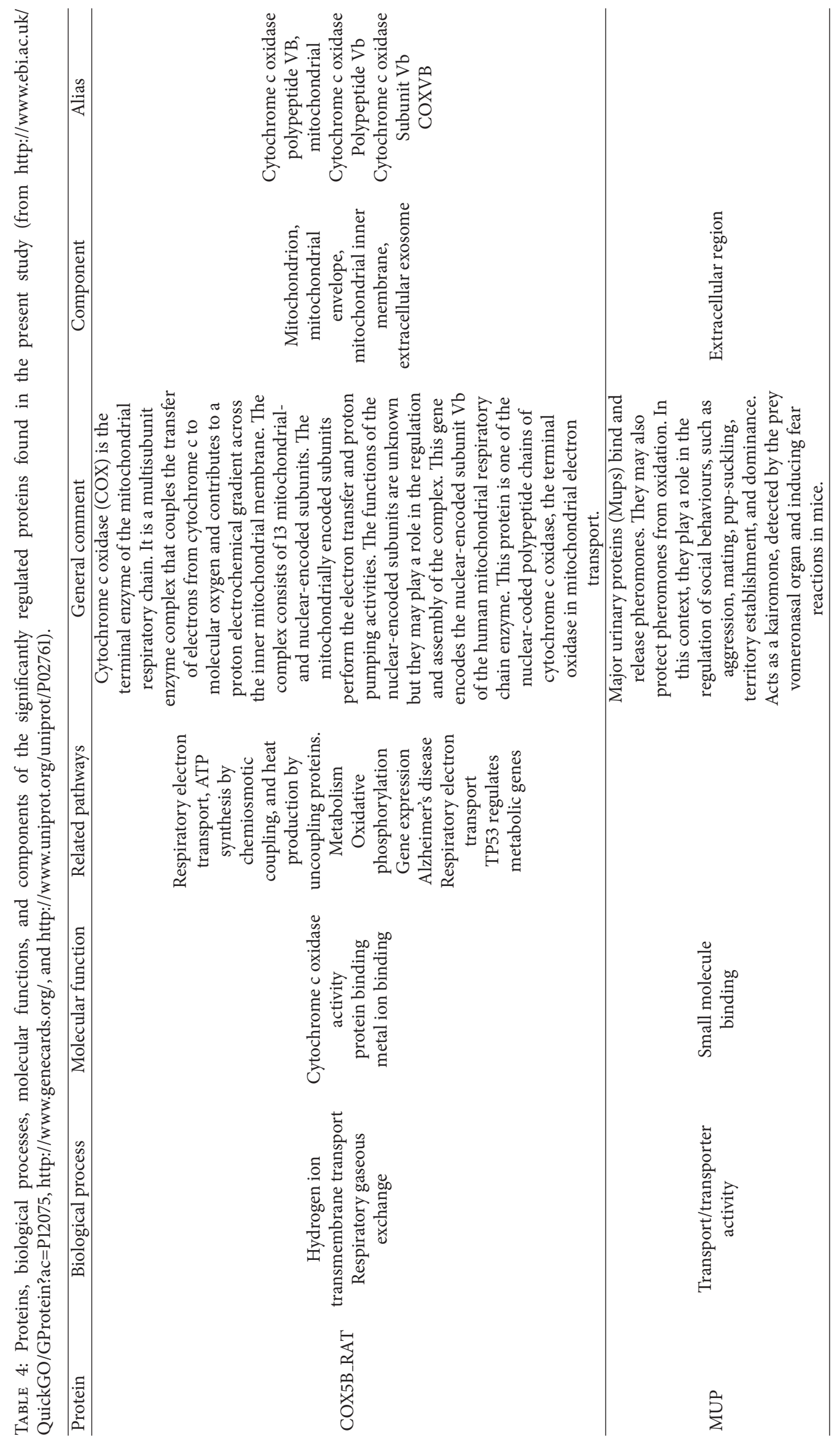




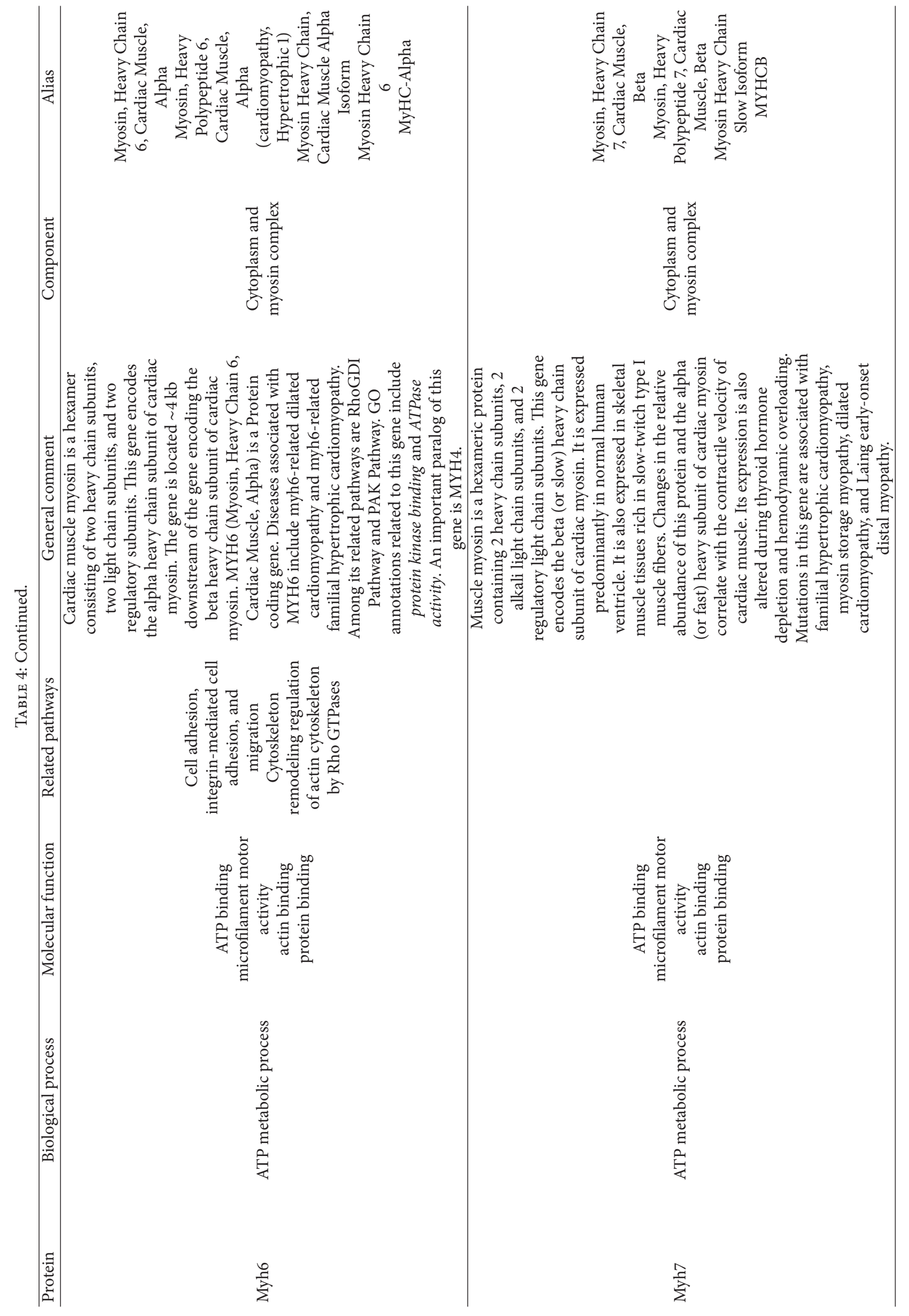




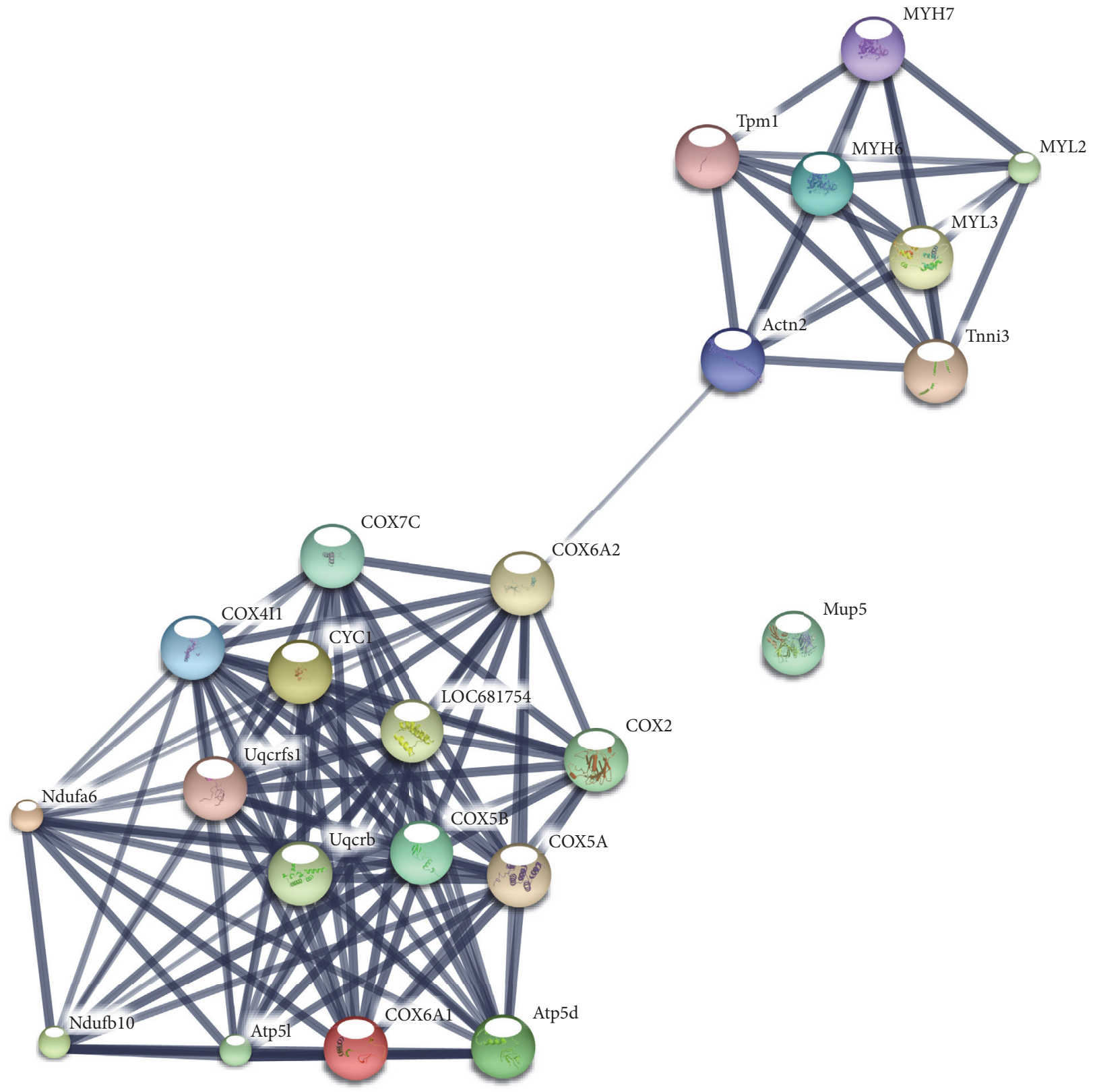

FIGURE 3: Protein network identified by STRING software (http://www.string-db.org/; confidence view, for MUP5, COX5b, MYH6, and MYH7). Thickness of the lines is directly proportional to the strong of connections among the nodes. Medium level of confidence (score 0.400 , with the maximum level of confidence at 0.900 and the lowest at 0.150 ) and no more than 20 nodes used. For other proteins in the network, see Table 5 . To generate the network, all significantly altered proteins were used for analysis, that is, pooled data from the 24 and 48 hours' group.

condition, with NO overexpression, antioxidant depletion, and reduction of ATP concentration, was found in skeletal muscle cells of sepsis human patients [51] and rats [52].

Association of COX5B with the kidney is not completely new. Tuma et al. also found COX5B being present in the porcine kidney, in both cortex and medulla [6]. Although this study did not analyze proteome alterations during sepsis and in piglets, it showed the importance of COX5B in the kidney. Fedorova et al. found COX4 less expressed in the fivesixth nephrectomy model of chronic renal failure of rats [53]. Expression of COX5B has also been shown to be associated with hypoxia and a low oxygen environment [41].

PGC-1 $\alpha$ (peroxisome proliferator-activated receptor- $\gamma$ coactivator- $1 \alpha)$ is a member of a small family of transcriptional regulators that controls the expression of genes involved in energy homeostasis, mitochondrial biogenesis, 


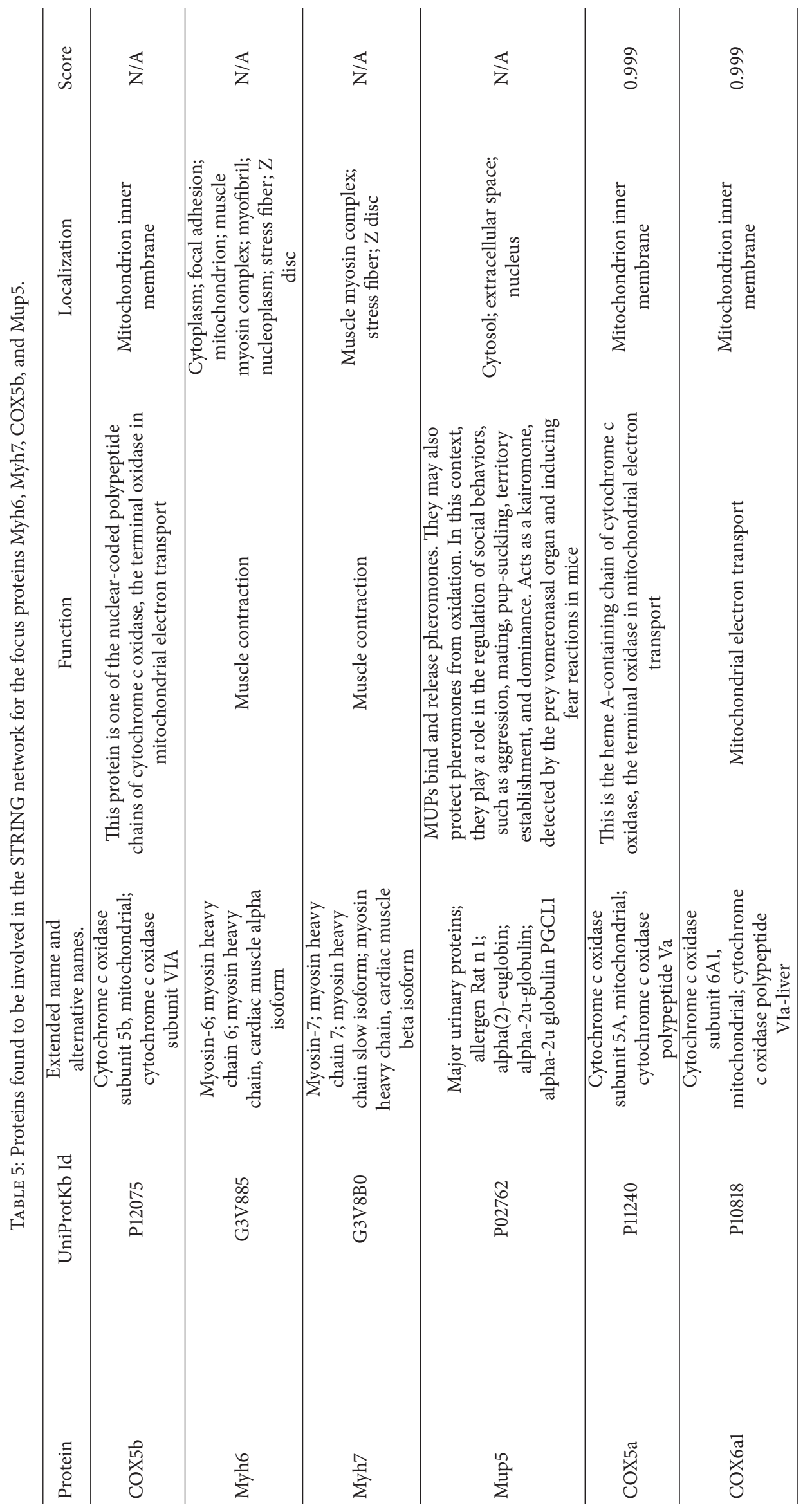




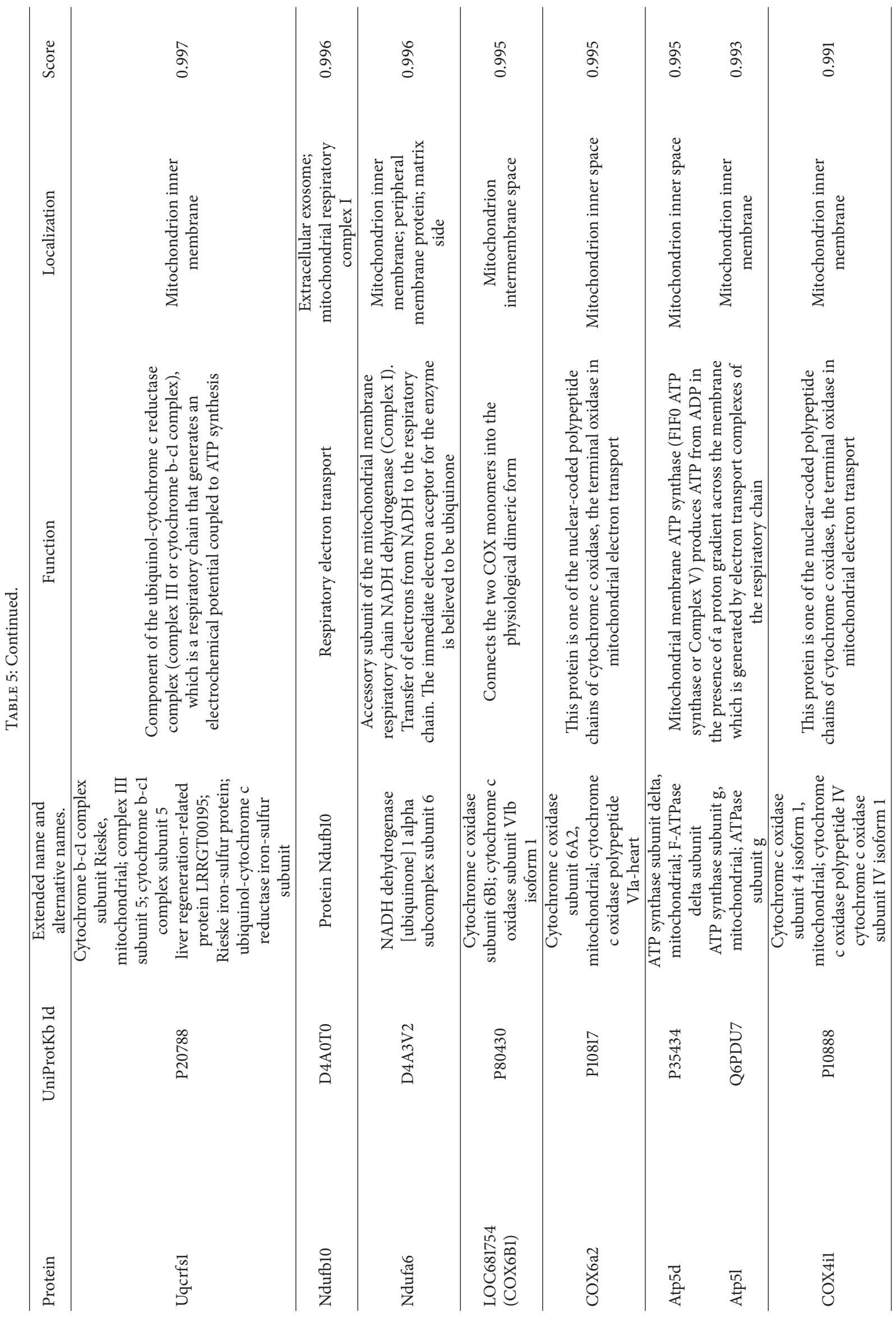




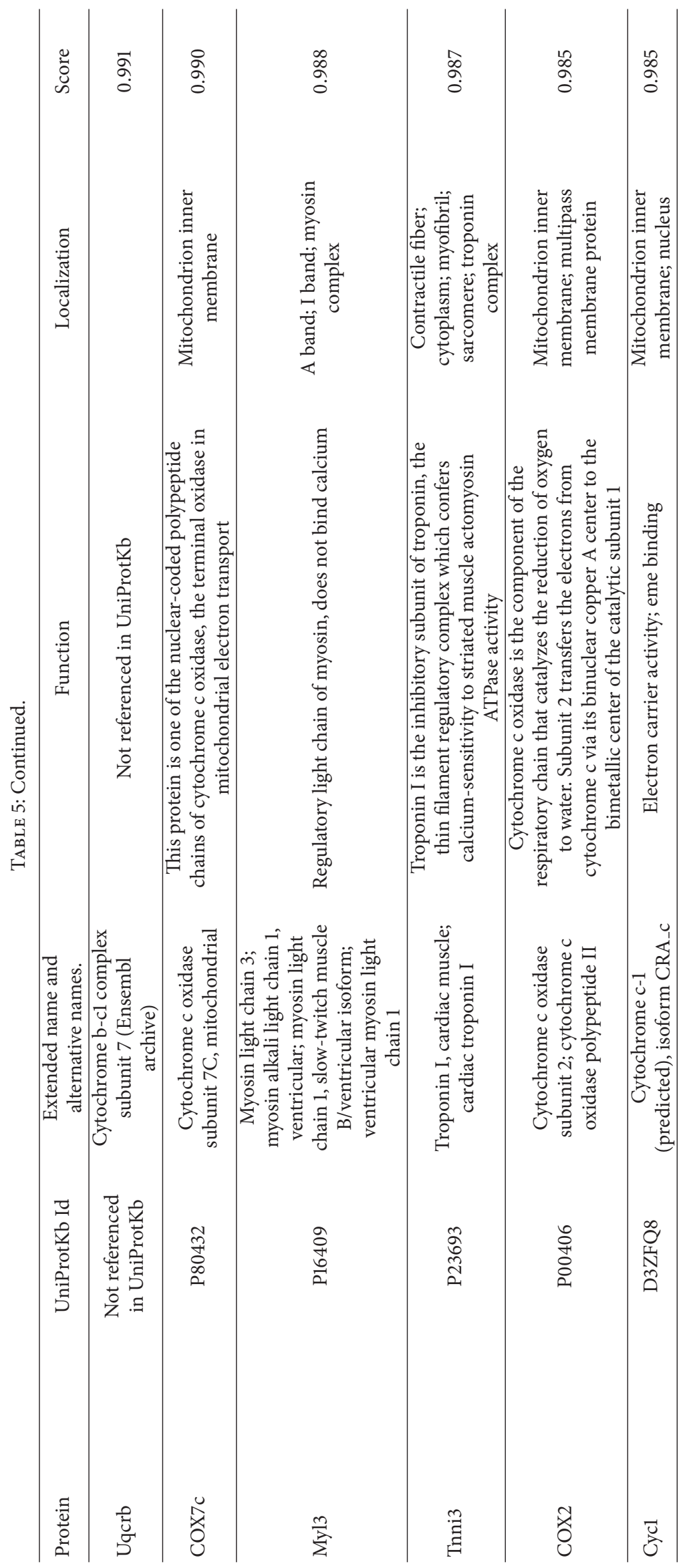




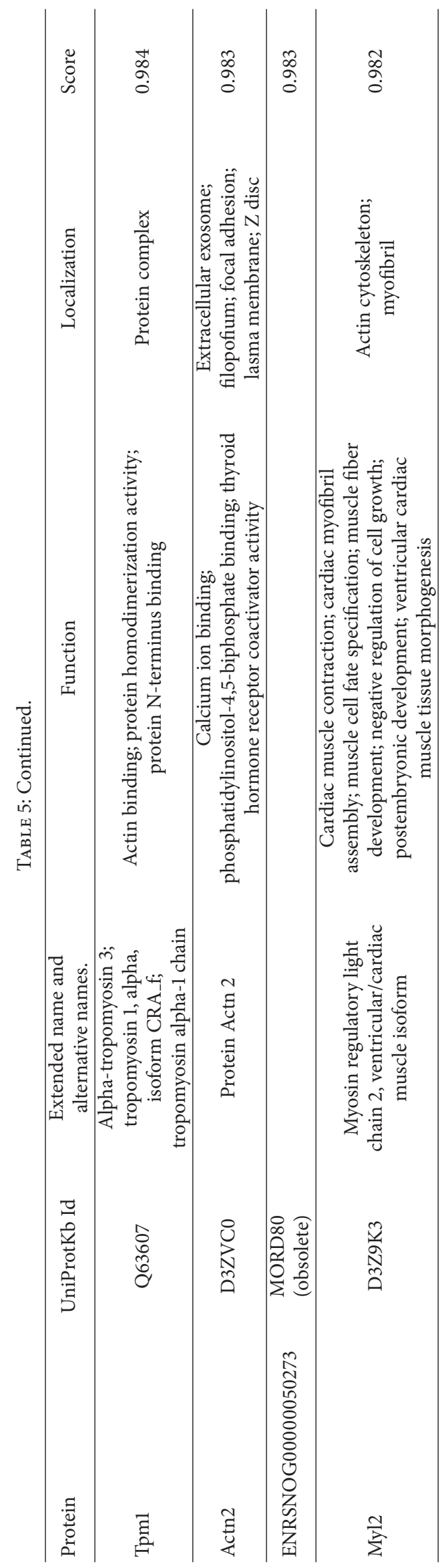




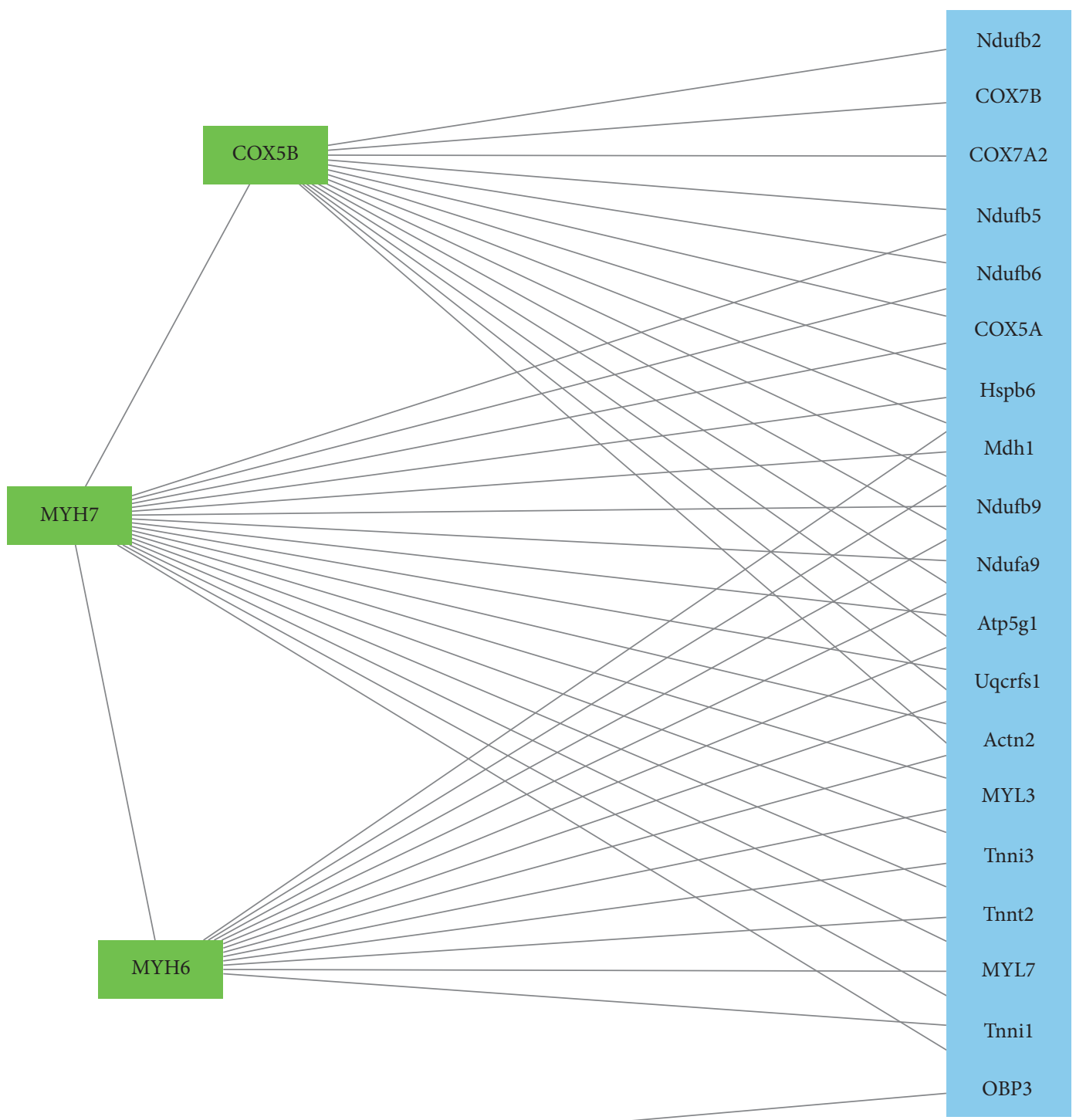

\section{MUP5}

Figure 4: GeneMANIA network (http://www.genemania.org/; visualization using Cytoscape, http://www.cytoscape.org/) found by search of significantly regulated proteins of the present study (i.e., MYH6, MYH7, COX5B, and MUP5). Proteins were entered to gather interactions. Green squares represent searched proteins and blue squares represent connections found by GeneMANIA. The identified proteins MUP5, COX5B, MYH6, and MYH7 are linked together within this network mainly by Atp5g1, COX5a, and OBP3. The lines show interactions between the nodes/proteins. To generate the network, all significantly altered proteins were used for analysis, that is, pooled data from the 24 and 48 hours' group.

fatty acid oxidation, and glucose metabolism [54]. PGC- $1 \alpha$ is pivotal for the mitochondrial function, as well as for the expression of key mitochondrial proteins [54]. Downregulation of PGC- $1 \alpha$ has been observed in different experimental models of AKI, and it is implicated as a causative event in renal functional impairment during sepsis-associated AKI [54]. Furthermore, expression of COX5B is regulated by PGC- $1 \alpha$ [54] and both proteins should be downregulated during emerging kidney injury. It may be speculated that sepsis with consecutive hypotension, altered perfusion, and possible hypoxia could have a comparable effect on COX5B expression.
However, this link between COX5B and PGC-1 $\alpha$ does not demonstrate validity or superiority of one protein in the context of a biomarker. Future studies should focus on the usefulness of both molecules as biomarkers in AKI.

4.3. MYH6 and MYH7. Myosin presence has been demonstrated in kidney descending vasa recta and in renal arterioles and could be involved in the regulation of the blood flow from descending vasa recta to capillary beds [55]. Myosin expressed in nonmuscle tissues plays a central role in cell adhesion, migration, and division [9]. Some other research revealed that MYL12A and MYL12B are crucial for 


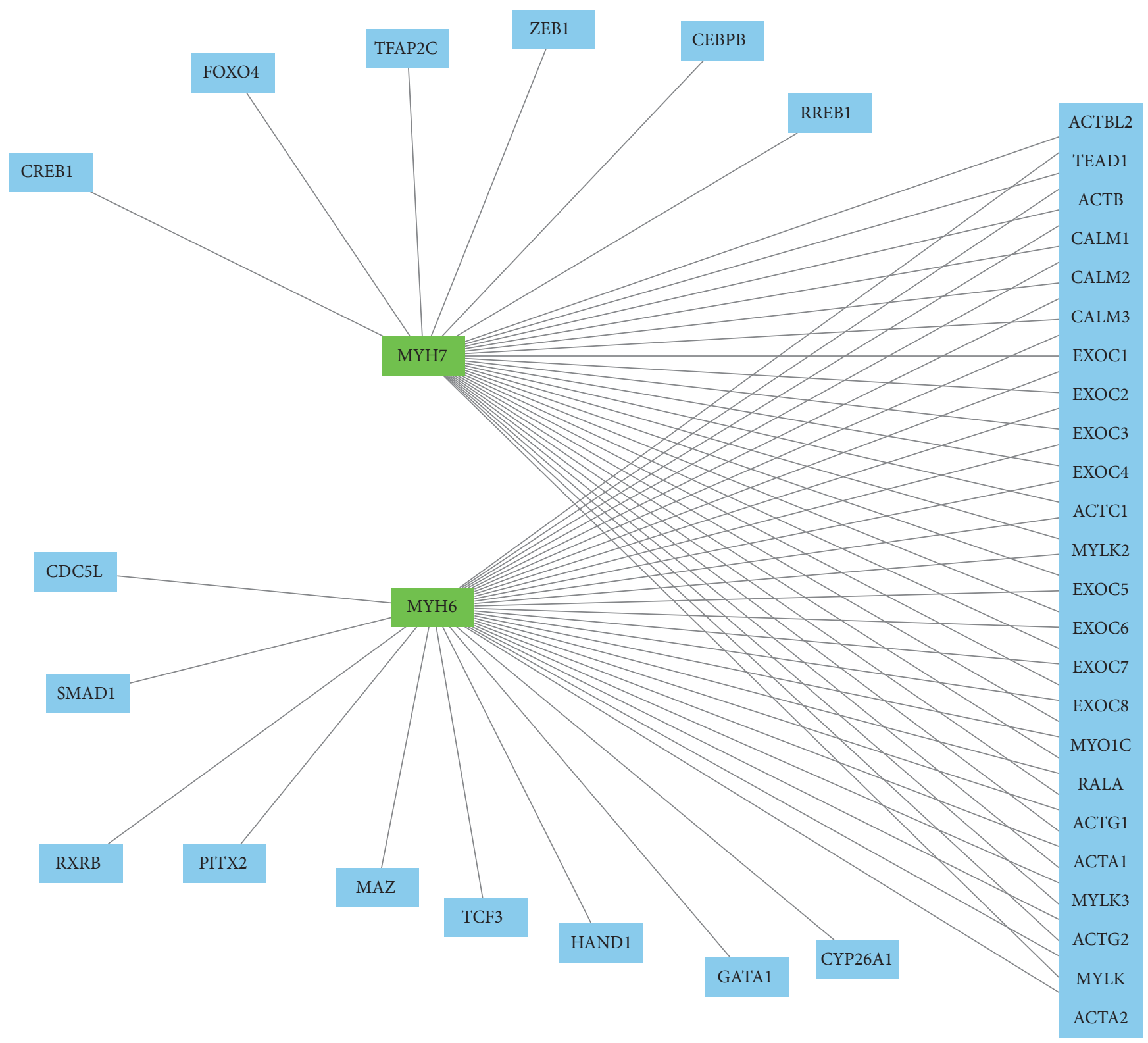

FIGURE 5: Protein network created by PCViz (Pathway Commons; http://www.pathwaycommons.org/; visualization using Cytoscape, http://www.cytoscape.org/). MYH6 and MYH7 are marked in green. All related proteins (blue nodes) are linked by lines to generate the network. COX5B and MUP5 proteins were not found to be present in this specific network. To generate the network, all significantly altered proteins were used for analysis, that is, pooled data from the 24 and 48 hours' group.

maintenance of the stability of MYH9, MYH10, and MYL6, which leads to normal cell actomyosin function [9].

It has been reported that myosin is implicated in endothelial barrier signaling [56]. Therefore, findings of the present study show that expression of myosin is altered during sepsis and could be a possible explanation for developing acute kidney injury during sepsis. However, it is not clear from the present point of view if the identified myosin originates from the kidney or was retained from filtration by the sepsisinjured kidney but was expressed elsewhere in the body. Furthermore, human skeletal muscle cells exposed to plasma of septic shock patients undergo a muscle protein loss with reduction of myosin, mostly in the early phase of sepsis [57].

4.4. MUP5. Also named as "alpha 2-U globulin," "alpha 2 euglobulin" is a rat protein synthetized in the liver, excreted via the kidneys and reabsorbed by up to $60 \%$ by the proximal tubule cells [58]. It is a precursor of a kidney fatty acidbinding protein, involved in mechanism of binding and transport of fatty acids (http://www.uniprot.org/) and it is overexpressed in renal cortex rather than medulla [59]. This protein can strongly bind toxic agents like alkans $[58,60]$ and is associated with the accumulation of hyaline droplet that 


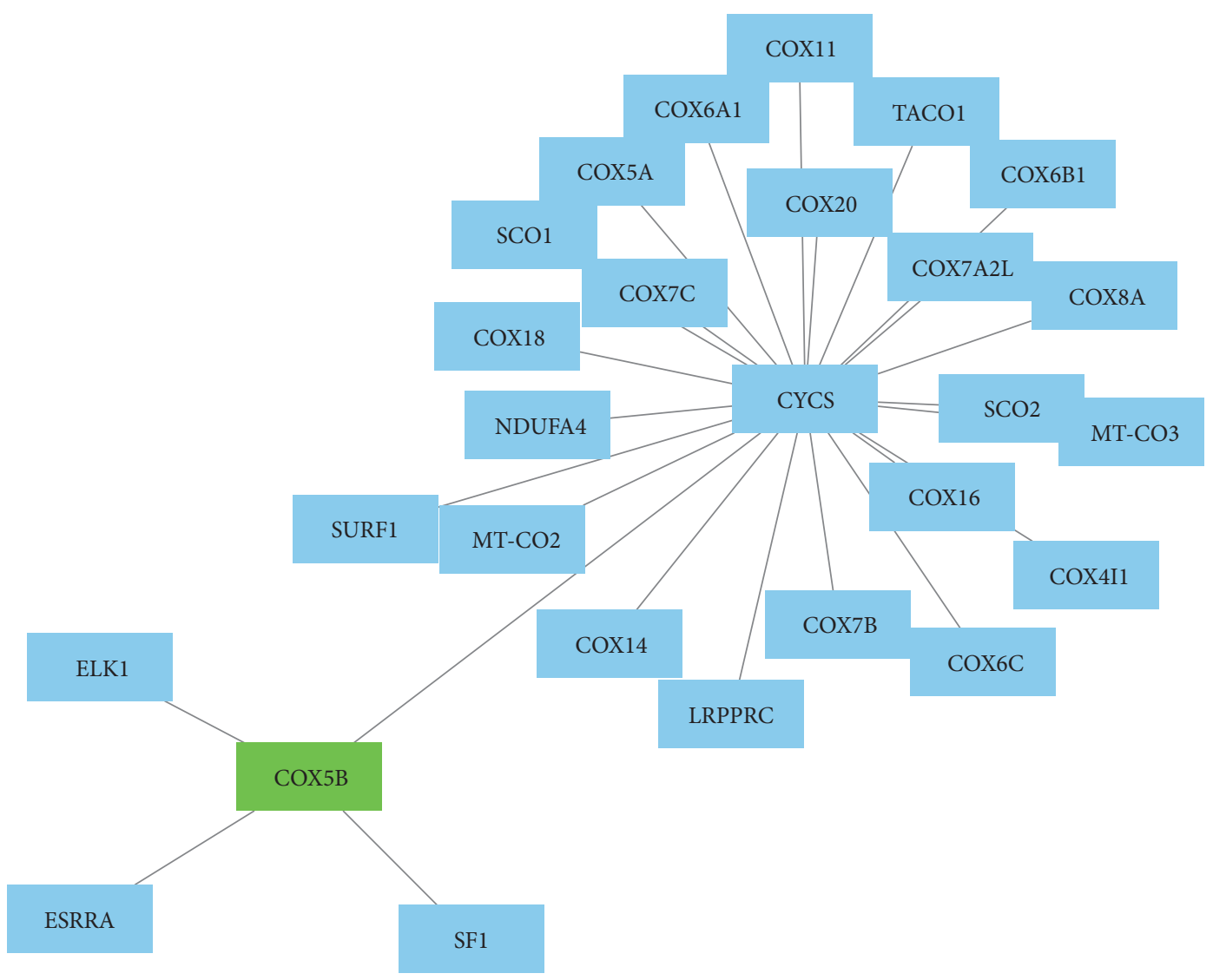

Figure 6: Protein network created by PCViz (Pathway Commons; http://www.pathwaycommons.org/; visualization using Cytoscape, http://www.cytoscape.org/). COX5B, in green, is centered and linked to other proteins via CYCS (human cytochrome c). MYH6 and MYH7 proteins were not found to be present in this specific network. To generate the network, all significantly altered proteins were used for analysis, that is, pooled data from the 24 and 48 hours' group.

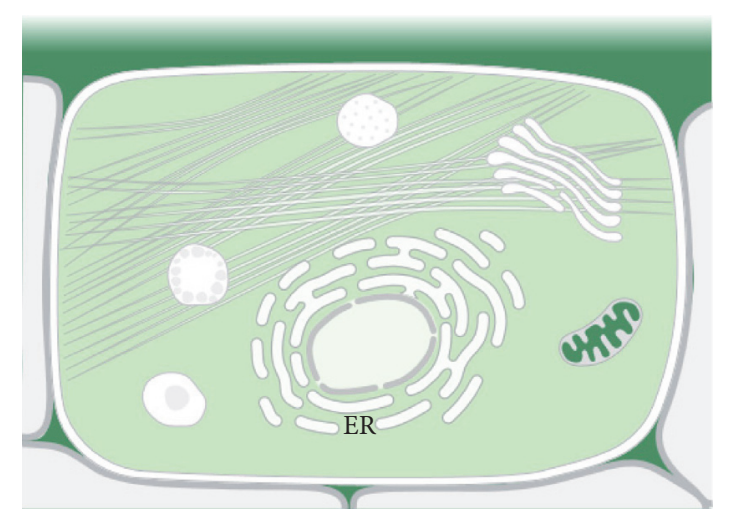

Confidence

$\begin{array}{ll}\square 0 & \square 3 \\ \square 1 & \square 4 \\ \square 2 & \square 5\end{array}$

FIGURE 7: COX5B localizations within a cell (from: subcellular locations, UniProtKB/Swiss-Prot for COX5B Gene). The location of COX5B within the cell is presented with statistic confidence: the darker the green color, the higher the probability for COX5B to be present in this location. 


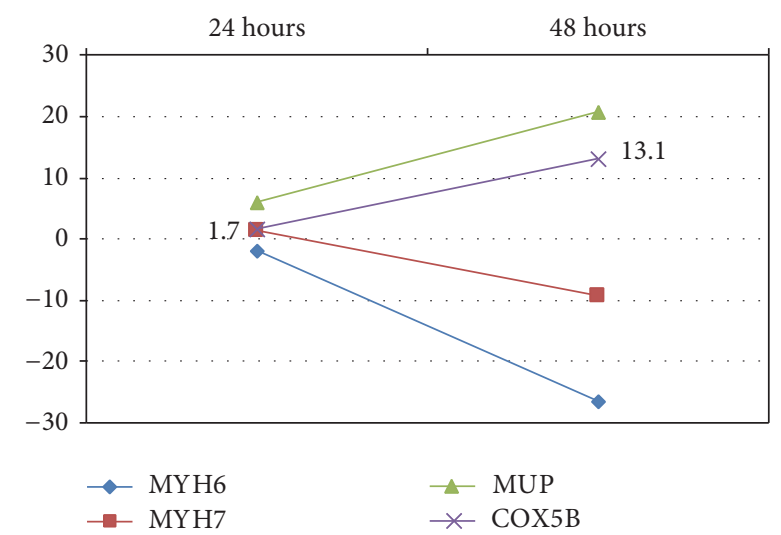

FIgURE 8: Spot ratios for the proteins identified. A positive value represents lower protein expression during sepsis. A negative value represents higher protein expression during sepsis. Values are shown against control group.

TABLE 6: Pathways associated with COX5B (from: http://www .genecards.org/).

\begin{tabular}{lc}
\hline Pathway & Database origin \\
\hline $\begin{array}{l}\text { Electron transport chain } \\
\text { Oxidative phosphorylation } \\
\text { Respiratory electron } \\
\text { transport, ATP synthesis by } \\
\text { chemiosmotic coupling, } \\
\text { and heat production by }\end{array}$ & $\begin{array}{c}\text { Wiki pathways } \\
\text { Wiki pathways }\end{array}$ \\
$\begin{array}{l}\text { uncoupling proteins } \\
\text { The citric acid (TCA) cycle } \\
\text { and respiratory electron } \\
\text { transport }\end{array}$ & Reactome \\
$\begin{array}{l}\text { Formation of ATP by } \\
\text { chemiosmotic coupling }\end{array}$ & Reactome \\
$\begin{array}{l}\text { Parkinson's disease } \\
\text { Huntington's disease }\end{array}$ & Reactome \\
Oxidative phosphorylation & KEGG \\
\hline
\end{tabular}

leads to damage of the proximal tubular epithelium and renal cancer $[61,62]$.

In our sample, MUP5 spot was localized at a significantly more alkaline $\mathrm{pI}$ than the other analyzed protein spots featuring this protein, suggesting some kind of posttranslational modification and/or degradation of MUP5 between $24 \mathrm{~h}$ and $48 \mathrm{~h}$ of sepsis.

4.5. Mitochondrial Dysfunction during Sepsis. Attempts to understand the regulation of cellular energy production in eukaryotic cells have focused on the components of the mitochondrial respiratory chain and its three sites of energy conservation [63]. Per milligram of tissue, only the heart exceeds the kidney's abundance of mitochondria [64]. The healthy nephron relies on mitochondrially generated ATP in order to facilitate the sodium-coupled reclamation of $99 \%$ filtered water [64]. Mitochondrial oxidative phosphorylation is responsible for over $90 \%$ of total body oxygen consumption and ATP generation. Segments of the nephron that perform the most chemical work are the proximal tubule and the thick ascending limb of Henle's loop [64].

The respiratory chain (electron-transport chain) includes four individual enzyme complexes (I-IV). These enzyme complexes, notably NADH-ubiquinone oxidoreductase (complex I) and cytochrome C oxidase (complex IV), can be inhibited by reactive oxygen and nitrogen species such as nitric oxide [5].

Cytochrome c oxidase is a key enzyme in the overall regulation of cellular energy production in eukaryotes [63]. Investigation into the underlying cellular mechanisms of AKI increasingly points towards a predominant role of mitochondria [7].

Ultrastructural changes in mitochondria are observed in kidney tubular cells during ischemic nephrotoxic, as well as sepsis-associated AKI, and result in functional decreases [64]. The changes include decreased mitochondrial mass, disruption of cristae, and extensive mitochondrial swelling [64]. These changes in mitochondria are often associated with functional decreases [64]. Mitochondrial dysfunction is, furthermore, also known as an important pathogenic factor in sepsis-associated multiorgan failure, including septic AKI [64]. It is noteworthy that the mitochondria-centered structural and metabolic or bioenergetic alterations occur prior to the onset of AKI, supporting a causative, pathogenic role of mitochondrial damage in this disease condition [64]. Taking into account these aspects, alterations in mitochondrial proteome could serve as potential biomarkers for sepsis-associated AKI.

Mitochondrial injury clearly arises in human sepsis, too, as evidenced by biochemical and structural studies on tissue biopsies obtained in intensive care settings [64]. Despite the recognition of mitochondrial dysfunction in AKI, the underlying mechanism is largely unclear [64]. Using the methodology of the present study, it can give additional insight into affected signaling cascades or tissue pathways. Mitophagy has also been described for the kidney in the course of sepsis [65].

4.6. AKI in the Context of the Present Study. In 2012, Hsiao et al. demonstrated a biphasic change of autophagy in the septic AKI (SAKI) model of CLP in rats [66]. Autophagy was shown to elevate at hours but then declined at 9 hours following CLP, where AKI was detected at 18 hours [64].

A considerable number of novel biomarkers for SAKI were developed during recent years and tested in clinical trials, such as cystatin c, neutrophil gelatinase-associated lipocalin (NGAL), interleukin-18 (IL-18), kidney injury molecule-1 (KIM-1), and liver-type fatty acid-binding protein (L-FABP); however, very little of value for earlier prognostication has transpired to date [9]. Therefore, screening of ideal biomarkers with highly sensitivity and specificity for AKI becomes very important and urgent [9]. Besides sepsis, also cis-platin-induced loss of renal function has been shown to be associated with a decreased expression of COX activity [64]. 
4.7. Study Limitations. There are some limitations of the present study which should be clearly addressed. First, validity of CLP model can be critically discussed. We used a standardized approach to induce sepsis and to get stable mortality rates. However, it is not completely clear to what extent rats suffered from acute kidney injury. Second, proteomics as molecular technique has some limitations itself, for example, problematic identification of low-abundant proteins. Analysis was performed standardized with the highest level of quality possible. But, it may be possible that other relevant proteins exist not being identified with the technique used. Third, due to the complex experimental setting and extensive techniques used, the number of rats used seems low. However, standardized approaches were implemented to minimize interrat variations as effective as possible. Fourth, it would be helpful to study the course of COX5B expression in both serum and urine at specific time points. However, since we did not collect urine, we have to refer to future studies to answer this question. Finally, we performed proteomics to identify altered tissue proteins. Therefore, interpretation of these results has to be careful and it has to take into account the fact that unknown mechanisms or protein interactions could exist.

\section{Conclusions and Future Aspects}

The present study analyzed proteome alterations in rat tissue during sepsis to identify possible biomarker candidates in the tissue. In summary, our study combines the power of proteomics with a classic animal model of sepsis.

COX5B could be a promising biomarker candidate since a significant association was found during experimental sepsis in the present study. For future research, COX5B should be evaluated as a biomarker in both human urine and serum to identify sepsis. Furthermore, it might be very interesting to compare this possible biomarker to other already known biomarkers for $\mathrm{AKD}$, for example, PGC1 $\alpha$ [8]. Unfortunately, it was not the focus of the present study to compare different biomarkers for AKD/AKI but future studies may focus on practicability and usability of different biomarkers in septic patients to find optimal and valid biomarkers.

In the future, it would be highly advantageous to identify biomarkers present in the urine or serum which would reveal AKD very early in its course [29] and to stratify patients and identify patients at risk for AKI. If the renal disease would be detected at a very early stage, reversal or cure might be possible [29].

\section{Competing Interests}

The authors declare no conflict of interests.

\section{Authors' Contributions}

Jochen Hinkelbein performed animal experimentation and wrote the manuscript together with Fabrizio Cirillo. Jochen Hinkelbein was responsible for revising the manuscript after the review. All authors improved the manuscript significantly. Lennert Böhm, Stefan Braunecker, Christoph Adler, and Edoardo De Robertis contributed significantly to data analysis, data interpretation, and writing the manuscript.

\section{References}

[1] M. Singer, C. Detschman, and C. Seymour, "The third international consesnus definitions for sepsis and septic shock (Sepsis3)," The Journal of the American Medical Association, vol. 315, no. 8, pp. 801-810, 2016.

[2] K. Doi, A. Leelahavanichkul, P. S. T. Yuen, and R. A. Star, "Animal models of sepsis and sepsis-induced kidney injury," The Journal of Clinical Investigation, vol. 119, no. 10, pp. 2868-2878, 2009.

[3] A. De Mendonça, J.-L. Vincent, P. M. Suter et al., "Acute renal failure in the ICU: risk factors and outcome evaluated by the SOFA score," Intensive Care Medicine, vol. 26, no. 7, pp. 915-921, 2000.

[4] D. C. Angus, W. T. Linde-Zwirble, J. Lidicker, G. Clermont, J. Carcillo, and M. R. Pinsky, "Epidemiology of severe sepsis in the United States: analysis of incidence, outcome, and associated costs of care," Critical Care Medicine, vol. 29, no. 7, pp. 1303-1310, 2001.

[5] D. Brealey, M. Brand, I. Hargreaves et al., "Association between mitochondrial dysfunction and severity and outcome of septic shock," Lancet, vol. 360, no. 9328, pp. 219-223, 2002.

[6] Z. Tuma, J. Kuncova, J. Mares, and M. Matejovic, "Mitochondrial proteomes of porcine kidney cortex and medulla: foundation for translational proteomics," Clinical and Experimental Nephrology, vol. 20, no. 1, pp. 39-49, 2016.

[7] M. Matejovic, Z. Tuma, J. Moravec et al., "Renal proteomic responses to severe sepsis and surgical trauma: dynamic analysis of porcine tissue biopsies," Shock, vol. 46, no. 4, pp. 453-464, 2016.

[8] M. Tran, D. Tam, A. Bardia et al., "PGC- $1 \alpha$ promotes recovery after acute kidney injury during systemic inflammation in mice," The Journal of Clinical Investigation, vol. 121, no. 10, pp. 4003-4014, 2011

[9] F. Wu, X.-J. Dong, Y.-Y. Li, Y. Zhao, Q.-L. Xu, and L. Su, "Identification of phosphorylated MYL12B as a potential plasma biomarker for septic acute kidney injury using a quantitative proteomic approach," International Journal of Clinical and Experimental Pathology, vol. 8, pp. 14409-14416, 2015.

[10] H. R. Wong, N. Z. Cvijanovich, N. Anas et al., "A multibiomarkerbased model for estimating the risk of septic acute kidney injury," Critical Care Medicine, vol. 43, no. 8, pp. 1646-1653, 2015.

[11] K. Doi, A. Leelahavanichkul, P. S. T. Yuen, and R. A. Star, "Animal models of sepsis and sepsis-induced kidney injury," Journal of Clinical Investigation, vol. 119, pp. 2868-2878, 2009.

[12] N. Gregersen, J. Hansen, and J. Palmfeldt, "Mitochondrial proteomics-a tool for the study of metabolic disorders," Journal of Inherited Metabolic Disease, vol. 35, no. 4, pp. 715-726, 2012.

[13] J. Hinkelbein, R. E. Feldmann Jr., A. Peterka et al., "Alterations in cerebral metabolomics and proteomic expression during sepsis," Current Neurovascular Research, vol. 4, no. 4, pp. 280288, 2007.

[14] J. Hinkelbein, A. Kalenka, and R. E. Feldmann Jr., "Early alterations in rat brain protein expression during sepsis," Anaesthesist, vol. 58, no. 2, pp. 134-143, 2009. 
[15] J. Hinkelbein, R. E. Feldmann Jr., C. Schubert et al., "Alterations in rat serum proteome and metabolome as putative disease markers in sepsis," The Journal of Trauma, vol. 66, no. 4, pp. 1065-1075, 2009.

[16] M. K. Holly, J. W. Dear, X. Hu et al., "Biomarker and drugtarget discovery using proteomics in a new rat model of sepsisinduced acute renal failure," Kidney International, vol. 70, no. 3, pp. 496-506, 2006.

[17] J. Hinkelbein, R. E. Feldmann Jr., and A. Kalenka, "Timedependent alterations of cerebral proteins following short-term normobaric hyperoxia," Molecular and Cellular Biochemistry, vol. 339, no. 1, pp. 9-21, 2010.

[18] O. Spelten, W. A. Wetsch, G. Wrettos, A. Kalenka, and J. Hinkelbein, "Response of rat lung tissue to short-term hyperoxia: a proteomic approach," Molecular and Cellular Biochemistry, vol. 383, no. 1-2, pp. 231-242, 2013.

[19] J. Hinkelbein, L. Böhm, O. Spelten, D. Sander, S. Soltész, and S. Braunecker, "Hyperoxia-induced protein alterations in renal rat tissue: a quantitative proteomic approach to identify hyperoxiainduced effects in cellular signaling pathways," Disease Markers, vol. 2015, Article ID 964263, 12 pages, 2015.

[20] Y. Wang, H. Liu, D. Liang et al., "Reveal the molecular signatures of hepatocellular carcinoma with different sizes by iTRAQ based quantitative proteomics," Journal of Proteomics, vol. 150, pp. 230-241, 2017.

[21] J. Hinkelbein, A. Kalenka, C. Schubert, A. Peterka, and R. E. Feldmann Jr., "Proteome and metabolome alterations in heart and liver indicate compromised energy production during sepsis," Protein \& Peptide Letters, vol. 17, no. 1, pp. 18-31, 2010.

[22] F. Lavatelli and G. Merlini, "Advances in proteomic study of cardiac amyloidosis: progress and potential," Expert Review of Proteomics, vol. 13, no. 11, pp. 1017-1027, 2016.

[23] J. Hinkelbein, A. Kalenka, C. Schubert, A. Peterka, and R. E. Feldmann Jr., "Proteome and metabolome alterations in heart and liver indicate compromised energy production during sepsis," Protein and Peptide Letters, vol. 17, no. 1, pp. 18-31, 2010.

[24] X. Peng, P. Xing, X. Li et al., "Towards personalized intervention for Alzheimer's disease," Genomics, Proteomics \& Bioinformatics, vol. 14, no. 5, pp. 289-297, 2016.

[25] M. Fasano, C. Monti, and T. Alberio, "A systems biology-led insight into the role of the proteome in neurodegenerative diseases," Expert Review of Proteomics, vol. 13, no. 9, pp. 845$855,2016$.

[26] M. G. Janech, J. R. Raymond, and J. M. Arthur, "Proteomics in renal research," American Journal of Physiology -Renal Physiology, vol. 292, no. 2, pp. F501-F512, 2007.

[27] J. Cohen, J.-L. Vincent, N. K. J. Adhikari et al., "Sepsis: a roadmap for future research," The Lancet Infectious Diseases, vol. 15, no. 5, pp. 581-614, 2015.

[28] S. M. Opal, R. P. Dellinger, J.-L. Vincent, H. Masur, and D. C. Angus, "The next generation of sepsis clinical trial designs: what is next after the demise of recombinant human activated protein C?" Critical Care Medicine, vol. 42, no. 7, pp. 1714-1721, 2014.

[29] T. Yamamoto, "Proteomics database in chronic kidney disease," Advances in Chronic Kidney Disease, vol. 17, no. 6, pp. 487-492, 2010.

[30] K. A. Wichterman, A. E. Baue, and I. H. Chaudry, "Sepsis and septic shock-a review of laboratory models and a proposal," Journal of Surgical Research, vol. 29, no. 2, pp. 189-201, 1980.

[31] W. J. Hubbard, M. Choudhry, M. G. Schwacha et al., "Cecal ligation and puncture," Shock, vol. 24, supplement 1, pp. 52-57, 2005.
[32] M. M. Bradford, "A rapid and sensitive method for the quantitation of microgram quantities of protein utilizing the principle of protein-dye binding," Analytical Biochemistry, vol. 72, no. 1-2, pp. 248-254, 1976.

[33] R. P. Tonge, J. Shaw, B. Middleton et al., "Validation and development of fluorescence two-dimensional differential gel electrophoresis proteomics technology," Proteomics, vol. 1, no. 3, pp. 377-396, 2001.

[34] D. Szklarczyk, A. Franceschini, S. Wyder et al., "STRING v10: protein-protein interaction networks, integrated over the tree of life," Nucleic Acids Research, vol. 43, no. 1, pp. D447-D452, 2014.

[35] B. Snel, G. Lehmann, P. Bork, and M. A. Huynen, "STRING: a web-server to retrieve and display the repeatedly occurring neighbourhood of a gene," Nucleic Acids Research, vol. 28, no. 18, pp. 3442-3444, 2000.

[36] C. von Mering, L. J. Jensen, B. Snel et al., "STRING: known and predicted protein-protein associations, integrated and transferred across organisms," Nucleic Acids Research, vol. 33, supplement 1, pp. D433-D437, 2005.

[37] D. Warde-Farley, S. L. Donaldson, O. Comes et al., "The GeneMANIA prediction server: biological network integration for gene prioritization and predicting gene function," Nucleic Acids Research, vol. 38, no. 2, pp. W214-W220, 2010.

[38] S. Mostafavi, D. Ray, D. Warde-Farley, C. Grouios, and Q. Morris, "GeneMANIA: a real-time multiple association network integration algorithm for predicting gene function," Genome Biology, vol. 9, supplement 1, article S4, 2008.

[39] H. Ogata, S. Goto, K. Sato, W. Fujibuchi, H. Bono, and M. Kanehisa, "KEGG: Kyoto encyclopedia of genes and genomes," Nucleic Acids Research, vol. 27, no. 1, pp. 29-34, 1999.

[40] E. G. Cerami, B. E. Gross, E. Demir et al., "Pathway Commons, a web resource for biological pathway data," Nucleic Acids Research, vol. 39, no. 1, pp. D685-D690, 2011.

[41] C. E. Trueblood, R. M. Wright, and R. O. Poyton, "Differential regulation of the two genes encoding Saccharomyces cerevisiae cytochrome c oxidase subunit V by heme and the HAP2 and REO1 genes," Molecular and Cellular Biology, vol. 8, no. 10, pp. 4537-4540, 1988.

[42] D. Rittirsch, L. M. Hoesel, and P. A. Ward, "The disconnect between animal models of sepsis and human sepsis," Journal of Leukocyte Biology, vol. 81, no. 1, pp. 137-143, 2007.

[43] P. Wang, M. Zhou, M. W. Rana, Z. F. Ba, and I. H. Chaudry, "Differential alterations in microvascular perfusion in various organs during early and late sepsis," American Journal of Physiology-Gastrointestinal and Liver Physiology, vol. 263, no. 1, pp. G38-G43, 1992.

[44] P. Wang and I. H. Chaudry, "Mechanism of hepatocellular dysfunction during hyperdynamic sepsis," American Journal of Physiology, vol. 270, no. 5, pp. R927-R938, 1996.

[45] S. Yang, W. G. Cioffi, K. I. Bland, I. H. Chaudry, and P. Wang, "Differential alterations in systemic and regional oxygen delivery and consumption during the early and late stages of sepsis," The Journal of Trauma, vol. 47, no. 4, pp. 706-712, 1999.

[46] Z. K. Zsengellér, L. Ellezian, D. Brown et al., "Cisplatin nephrotoxicity involves mitochondrial injury with impaired tubular mitochondrial enzyme activity," Journal of Histochemistry and Cytochemistry, vol. 60, no. 7, pp. 521-529, 2012.

[47] N. S. Chandel, E. Maltepe, E. Goldwasser, C. E. Mathieu, M. C. Simon, and P. T. Schumacker, "Mitochondrial reactive oxygen species trigger hypoxia-induced transcription," Proceedings of 
the National Academy of Sciences of the United States of America, vol. 95, no. 20, pp. 11715-11720, 1998.

[48] M. R. Hodge, G. Kim, K. Singh, and M. G. Cumsky, "Inverse regulation of the yeast COX5 genes by oxygen and heme," Molecular and Cellular Biology, vol. 9, no. 5, pp. 1958-1964, 1989.

[49] P. V. Burke, D. C. Raitt, L. A. Allen, E. A. Kellogg, and R. O. Poyton, "Effects of oxygen concentration on the expression of cytochrome c and cytochrome c oxidase genes in yeast," The Journal of Biological Chemistry, vol. 272, no. 23, pp. 14705-14712, 1997.

[50] P. R. Castello, P. S. David, T. McClure, Z. Crook, and R. O. Poyton, "Mitochondrial cytochrome oxidase produces nitric oxide under hypoxic conditions: implications for oxygen sensing and hypoxic signaling in eukaryotes," Cell Metabolism, vol. 3, no. 4, pp. 277-287, 2006.

[51] D. Brealey, M. Brand, I. Hargreaves et al., "Association between mitochondrial dysfunction and severity and outcome of septic shock," The Lancet, vol. 360, no. 9328, pp. 219-223, 2002.

[52] D. Brealey, S. Karyampudi, T. S. Jacques et al., "Mitochondrial dysfunction in a long-term rodent model of sepsis and organ failure," American Journal of Physiology-Regulatory Integrative and Comparative Physiology, vol. 286, no. 3, pp. R491-R497, 2004.

[53] L. V. Fedorova, A. Tamirisa, D. J. Kennedy et al., "Mitochondrial impairment in the five-sixth nephrectomy model of chronic renal failure: proteomic approach," BMC Nephrology, vol. 14, no. 1, article 209, 2013.

[54] O. Ruiz-Andres, B. Suarez-Alvarez, C. Sánchez-Ramos et al., "The inflammatory cytokine TWEAK decreases PGC-1 $\alpha$ expression and mitochondrial function in acute kidney injury," Kidney International, vol. 89, no. 2, pp. 399-410, 2015.

[55] G. Wei, S. Rosen, W. H. Dantzler, and T. L. Pannabecker, "Architecture of the human renal inner medulla and functional implications," American Journal of Physiology - Renal Physiology, vol. 309, no. 7, pp. F627-F637, 2015.

[56] R. R. Rigor, Q. Shen, C. D. Pivetti, M. H. Wu, and S. Y. Yuan, "Myosin light chain kinase signaling in endothelial barrier dysfunction," Medicinal Research Reviews, vol. 33, no. 5, pp. 911933, 2013.

[57] H. W. H. van Hees, W.-J. M.-J. Schellekens, M. Linkels et al., "Plasma from septic shock patients induces loss of muscle protein," Critical Care, vol. 15, article R233, 2011.

[58] N. P. Page and M. Mehlman, "Health effects of gasoline refueling vapors and measured exposures at service stations," Toxicology and Industrial Health, vol. 5, no. 5, pp. 869-890, 1989.

[59] J. M. Arthur, V. Thongboonkerd, J. A. Scherzer, J. Cai, W. M. Pierce, and J. B. Klein, "Differential expression of proteins in renal cortex and medulla: a proteomic approach," Kidney International, vol. 62, no. 4, pp. 1314-1321, 2002.

[60] M. Hamamura, A. Hirose, E. Kamata et al., "Semi-quantitative immunohistochemical analysis of male rat-specific $\alpha 2 \mathrm{u}-$ globulin accumulation for chemical toxicity evaluation," Journal of Toxicological Sciences, vol. 31, no. 1, pp. 35-47, 2006.

[61] J. A. Swenberg, B. Short, S. Borghoff, J. Strasser, and M. Charbonneau, "The comparative pathobiology," Toxicology and Applied Pharmacology, vol. 46, pp. 35-46, 1989.

[62] K. Uchida, A. Fukuda, S. Kawakishi et al., "Acute nephrotoxicity of a carcinogenic iron chelate Selective inhibition of a proteolytic conversion of $\alpha_{2 U}$-globulin to the kidney fatty acidbinding protein," FEBS Letters, vol. 357, no. 2, pp. 165-167, 1995.
[63] R. O. Poyton, C. E. Trueblood, R. M. Wright, and L. E. Farrell, "Expression and function of cytochrome c oxidase subunit isologues. Modulators of cellular energy production?" Annals of the New York Academy of Sciences, vol. 550, pp. 289-307, 1988.

[64] S. M. Parikh, Y. Yang, L. He, C. Tang, M. Zhan, and Z. Dong, "Mitochondrial function and disturbances in the septic kidney," Seminars in Nephrology, vol. 35, no. 1, pp. 108-119, 2015.

[65] H. Gomez, C. Ince, D. De Backer et al., "A unified theory of sepsis-induced acute kidney injury: inflammation, microcirculatory dysfunction, bioenergetics, and the tubular cell adaptation to injury," Shock, vol. 41, no. 1, pp. 3-11, 2014.

[66] H.-W. Hsiao, K.-L. Tsai, L.-F. Wang et al., "The decline of autophagy contributes to proximal tubular dysfunction during sepsis," Shock, vol. 37, no. 3, pp. 289-296, 2012. 


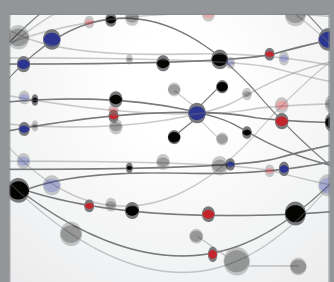

The Scientific World Journal
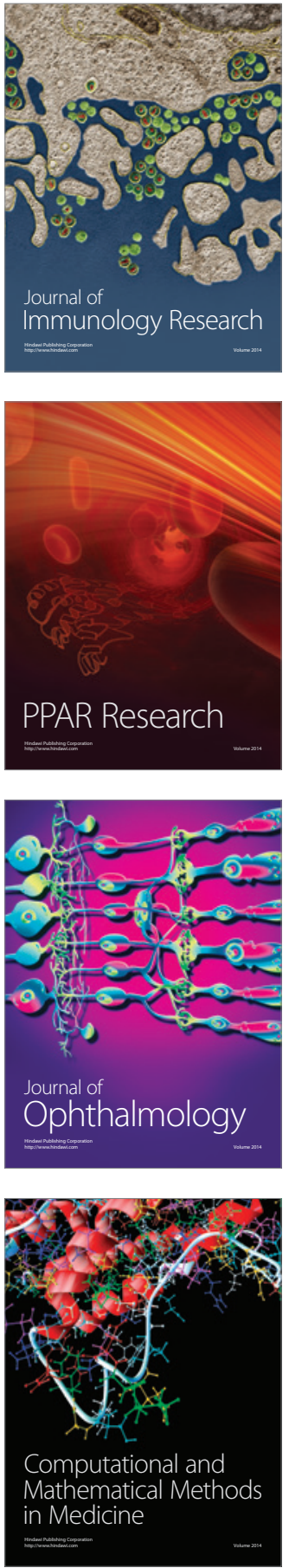

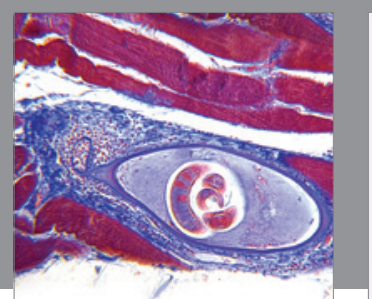

Gastroenterology Research and Practice
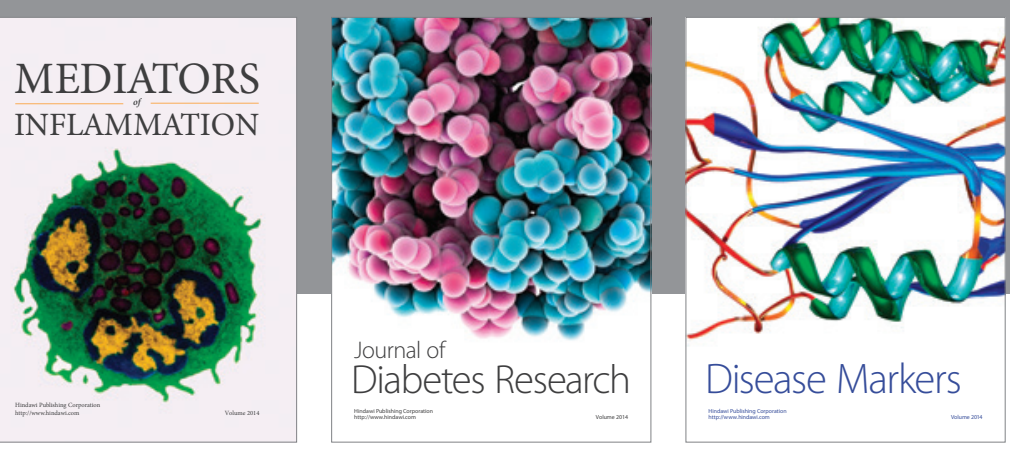

Disease Markers

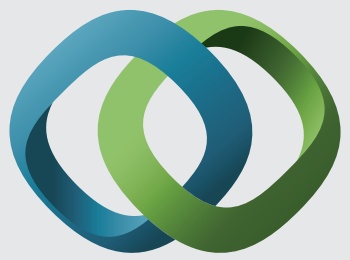

\section{Hindawi}

Submit your manuscripts at

https://www.hindawi.com
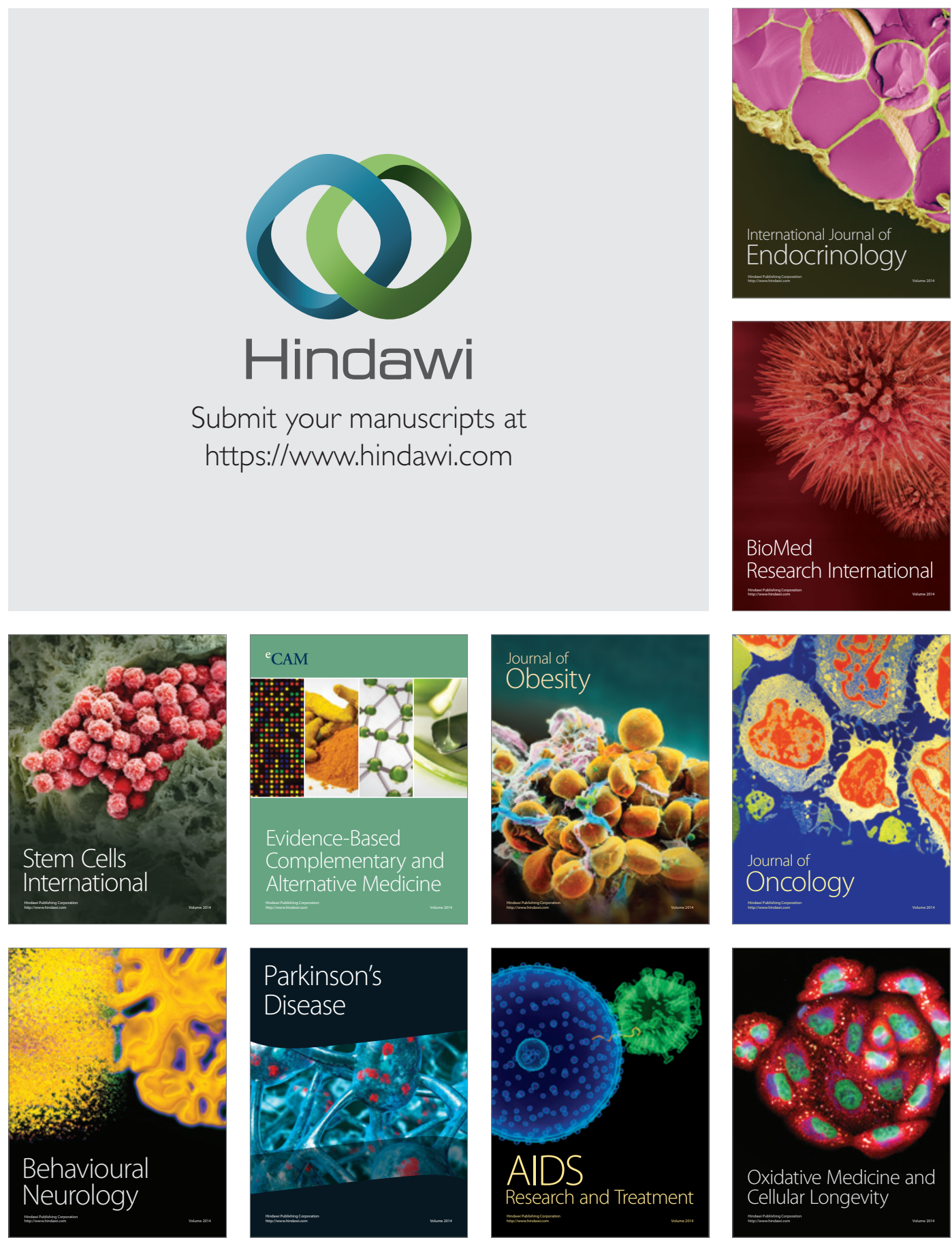